Research Article

\title{
Noise Source Separation of an Internal Combustion Engine Based on a Single-Channel Algorithm
}

\author{
Jiachi Yao $\mathbb{D}$, Yang Xiang $(\mathbb{D}$, Sichong Qian, and Shuai Wang \\ School of Energy and Power Engineering, Wuhan University of Technology, Wuhan 430063, China \\ Correspondence should be addressed to Yang Xiang; yxiang@whut.edu.cn
}

Received 21 February 2019; Revised 7 June 2019; Accepted 17 June 2019; Published 11 July 2019

Academic Editor: Xavier Chiementin

Copyright (c) 2019 Jiachi Yao et al. This is an open access article distributed under the Creative Commons Attribution License, which permits unrestricted use, distribution, and reproduction in any medium, provided the original work is properly cited.

\begin{abstract}
The separation and identification technology of noise sources is the focus and hot spot in the field of internal combustion engine noise research. Combustion noise and piston slap noise are the main noise sources of an internal combustion engine. However, both combustion noise and piston slap noise occur almost at the top dead center. They mix in the time domain and frequency domain. It is difficult to accurately and effectively separate them. A single-channel algorithm which combines time-varying filtering-based empirical mode decomposition (TVF-EMD) and robust independent component analysis (RobustICA) methods is proposed to separate them. Firstly, the TVF-EMD method is utilized to decompose the single-channel noise signal into several intrinsic mode functions (IMFs). Then, the RobustICA method is applied to extract the independent components. Finally, related prior knowledge and time-frequency analysis are employed to identify noise sources. Furthermore, the spectral filtering method and the calculation method of piston slap noise based on the dynamic model are further carried out to verify separation results. The simulation and experimental research results show the effectiveness of the proposed method.
\end{abstract}

\section{Introduction}

The internal combustion engine has been widely used in a variety of transportation vehicles, such as ships and automobiles [1]. However, when the internal combustion engine is working, it generates huge noise in the surrounding environment. Noise can disturb people's daily life and even endanger people's health. Therefore, noise problem has become a growing concern of society. When people are exposed to noise for a long time, it can cause insomnia, cardiovascular disease, and even death $[2,3]$. The global legislative committee is developing strict regulations to make ships, cars, and other transportation vehicles quieter [4].

As the main power source and noise source of ships and automobiles, the internal combustion engine has a significant impact on the total noise level [5]. Therefore, it is urgent to study the corresponding method to reduce the noise level of internal combustion engines. The primary task of reducing the noise of internal combustion engines is to study and analyze the characteristics of each noise source of internal combustion engines and then to develop a corresponding targeted and efficient noise reduction scheme. Thus, separating various noise sources of internal combustion engines has become a hot topic in the field of internal combustion engine noise research.

The noise source of the internal combustion engine is mainly composed of combustion noise, piston slap noise, gear noise, valve knock noise, fuel pump noise, and so forth [6]. Among these noise sources, combustion noise and piston slap noise account for $80 \%$ of the total noise [7]. They are the main noise sources of the internal combustion engine. By reducing the combustion noise and piston slap noise, the total noise will be significantly reduced. Therefore, it is necessary to study the combustion noise and piston slap noise.

However, the combustion noise and piston slap noise almost occur near the top dead center, and they severely alias in the time-frequency domain. Thus, it is very difficult to separate them. Currently, some scientists use the multichannel algorithm to separate noise sources, such as blind source separation method [8], independent component analysis method [9], independent component and wavelet 
analysis method [10], improved spectrofilter method [11], hierarchy diagnosis coherent power spectrum analysis method [12], and acoustic holography and sound intensity method [13].

However, in the practical engineering applications, due to the sensor cost and installation conditions, generally only fewer sensors can be used. The multichannel algorithm is limited in practical engineering applications. Therefore, many scientists begin to study the single-channel algorithm to separate noise sources. For example, Du et al. [14] used the EMD and independent component analysis methods to separate the combustion excitation signal and piston slap signal. Bi et al. [15] employed the EEMD-RobustICA method to separate the combustion noise, piston slap noise, and exhaust noise of gasoline engines. Zhang et al. [16] utilized the EEMD, coherent power spectrum analysis, and improved analytic hierarchy process method to identify the noise sources of internal combustion engines. Zheng et al. [17] employed the EEMD and generalized $S$ transform methods to separate the combustion noise, piston slap noise, gear noise, and so forth.

The current single-channel algorithm is mainly based on the EMD method and EEMD method to separate the noise sources of internal combustion engines. Besides, there are also some other methods such as the VMD-based method [18] and Gammatone-based method [19]. But the VMDbased method needs to set complex parameters, and the separation result is greatly affected by the setting parameters. The Gammatone-based method is mainly used to separate mixed speech signals. As for the EMD method, it has the mode-mixing and end effect problems $[20,21]$. Although the EEMD method can overcome the mode-mixing problem, the selection of the parameters such as added noise amplitude and ensemble number is difficult to determine, and they have a great influence on the effect of signal decomposition [22]. In addition, the computational cost of the EEMD method is high [23].

Recently, the novel time-varying filtering-based empirical mode decomposition (TVF-EMD) which was proposed by $\mathrm{Li}$ et al. could effectively solve the separation problem and the intermittence problem, and it has a better decomposition performance than the EMD method [24]. The TVF-EMD method is a data-driven adaptive decomposition method, and it has been applied in bearing fault diagnosis [25, 26], wind speed forecasting [27], modal identification [28], etc. In this paper, the TVF-EMD method is explored and applied to the noise source separation of an internal combustion engine. Because the TVF-EMD method has the excellent signal decomposition ability and the RobustICA method has the outstanding ability to extract independent components from the mixed components, the single-channel algorithm which combines TVF-EMD and RobustICA methods is proposed to separate the internal combustion engine noise sources. Firstly, the single-channel noise signal is decomposed into several IMFs by the TVF-EMD method. Then, the RobustICA method is carried out to extract the independent components. Finally, related prior knowledge and time-frequency analysis are utilized to identify noise sources. The main contribution of this paper is to propose a single-channel algorithm based on the TVF-EMD and RobustICA methods to separate the noise sources of internal combustion engines. Moreover, the independent combustion noise calculation method (the spectral filtering method) and the piston slap noise calculation method (the calculation method of piston slap noise based on the dynamic model) are integrated together to verify the separation results of the combustion noise and piston slap noise. The separation method and calculation flow of noise sources of the internal combustion engine are obtained.

\section{Related Methods}

2.1. TVF-EMD Method. The time-varying filtering-based empirical mode decomposition (TVF-EMD) can adaptively decompose the nonstationary signals. Compared with the EMD method, the TVF-EMD method solved the separation problem and the intermittence problem [24]. Hence, the TVF-EMD method has better separation ability than the EMD method, especially in terms of nonstationary signals. The calculation steps of the TVF-EMD method are as follows:

Step 1: for the signal $x(t)$, use the Hilbert transform to calculate the instantaneous amplitude $A(t)$ and the instantaneous frequency $\varphi^{\prime}(t)$.

Step 2: locate the local maxima $A\left(\left\{t_{\max }\right\}\right)$ and the local minima $A\left(\left\{t_{\min }\right\}\right)$.

Step 3: interpolate the set of points $A\left(\left\{t_{\min }\right\}\right)$ and $A\left(\left\{t_{\max }\right\}\right)$ to obtain $\beta_{1}(t)$ and $\beta_{2}(t)$. Then, $a_{1}(t)=\left[\beta_{1}(t)+\beta_{2}(t)\right] / 2$ and $a_{2}(t)=\left[\beta_{2}(t)-\beta_{1}(t)\right] / 2$. Step 4: interpolate the $\varphi^{\prime}\left(\left\{t_{\min }\right\}\right) A^{2}\left(\left\{t_{\min }\right\}\right)$ and $\varphi^{\prime}\left(\left\{t_{\max }\right\}\right) A^{2}\left(\left\{t_{\max }\right\}\right)$ to obtain $\eta_{1}(t)$ and $\eta_{2}(t)$. Then,

$$
\begin{aligned}
\varphi_{1}^{\prime}(t) & =\frac{\eta_{1}(t)}{2 a_{1}^{2}(t)-2 a_{1}(t) a_{2}(t)}+\frac{\eta_{2}(t)}{2 a_{1}^{2}(t)+2 a_{1}(t) a_{2}(t)}, \\
\varphi_{2}^{\prime}(t) & =\frac{\eta_{1}(t)}{2 a_{2}^{2}(t)-2 a_{1}(t) a_{2}(t)}+\frac{\eta_{2}(t)}{2 a_{2}^{2}(t)+2 a_{1}(t) a_{2}(t)} .
\end{aligned}
$$

Step 5: calculate the local cutoff frequency through $\varphi_{\text {bis }}^{\prime}(t)=\left(\varphi_{1}^{\prime}(t)+\varphi_{2}^{\prime}(t)\right) / 2=\left(\eta_{2}(t)-\eta_{1}(t)\right) /\left(4 a_{1}(t)\right.$ $\left.a_{2}(t)\right)$.

Step 6: adjust $\varphi_{\text {bis }}^{\prime}(t)$ to solve the intermittence problem.

Step 7: then, $h(t)=\cos \left[\int \varphi_{\text {bis }}^{\prime}(t) d t\right]$. The B-spline approximation is applied on $x(t)$, and the extreme timings of $h(t)$ is taken the knots. The approximate result can be obtained as $m(t)$.

Step 8: if the stopping criterion $\theta(t) \leq \zeta$, then an IMF of $x(t)$ is obtained. Otherwise, let $x(t)=x(t)-m(t)$ and continue to perform Step 1 to Step 7.

In the TVF-EMD method, the bandwidth $\zeta$ and B-spline order $n$ are the key parameters which need to be set in advance. According to [24], considering the computational cost and algorithm performance, these two parameters are adopted the default values, $\zeta=0.1$ and $n=28$. 
Considering that the TVF-EMD method has to be used in the nonstationary noise signal of the internal combustion engine, three nonstationary simulated signals are selected to illustrate the decomposition performance of the TVF-EMD method. The simulated signals are shown in equation (2). The sampling frequency is $512 \mathrm{~Hz}$. The timedomain waveform of the simulated signal is shown in Figure 1:

$$
\begin{aligned}
S 1 & =\cos \left(2 \pi \cdot 33 \cdot t+50 \pi \cdot t^{2}\right), \\
S 2 & =\cos \left(2 \pi \cdot 56 \cdot t+50 \pi \cdot t^{2}\right), \\
S 3 & =\cos \left(2 \pi \cdot 94 \cdot t+50 \pi \cdot t^{2}\right), \\
S & =S 1+S 2+S 3 .
\end{aligned}
$$

Then, the EMD method and TVF-EMD method are utilized to decompose the mixed signal. The calculation results are shown in Figures 2 and 3.

As shown in Figure 2, it can be seen that the calculation results by the EMD method have large difference with the original simulation signal, especially shown in the red circle. From Figure 3, the calculation results by the TVF-EMD method are similar with the original simulation signal, IMF1 corresponds to $S 1$, IMF2 corresponds to $S 2$, and IMF3 corresponds to $S 3$.

In order to quantitatively compare the separation performance of the two methods, the following index was employed to calculate the matching degree between the separated signal and the original signal [29]:

$$
\text { index }(\mathrm{IMF} n)=-20 * \log 10\left(\frac{\|\mathrm{IMF} n-S n\|}{\|S n\|}\right),
$$

where $n=1,2,3$. The quantitative index on the performance of EMD and TVF-EMD methods is shown in Table 1.

According to equation (3), the larger the index is, the better the separation effect is. From Table 1, the TVF-EMD method provided the best recovery $S 3$ by the largest index $18.9132 \mathrm{~dB}$, which was consistent with the results in Figure 3. As for $S 1$ and $S 2$, the index is also larger than the EMD method. The average index of the calculated results by the TFM-EMD method is $16.9058 \mathrm{~dB}$. But the EMD only scored $3.2405 \mathrm{~dB}$. From the above analysis, it is inferred that the TVF-EMD method presents a better decomposition performance than the EMD method.

2.2. RobustICA Method. The separation process of the ICA method is to find a transformation matrix $W$ of the observation mixed signal $X(t)$ to make the output $y(t)$ as independent as possible [30]:

$$
y(t)=W X(t)+N,
$$

where $W$ is the unmixing matrix and $N$ is the additional noise.

The commonly used ICA method has the FastICA [31] and JADE [32]. However, the FastICA and JADE methods have some problems such as low computational accuracy and insufficient robustness. Later, Zarzoso and Comon
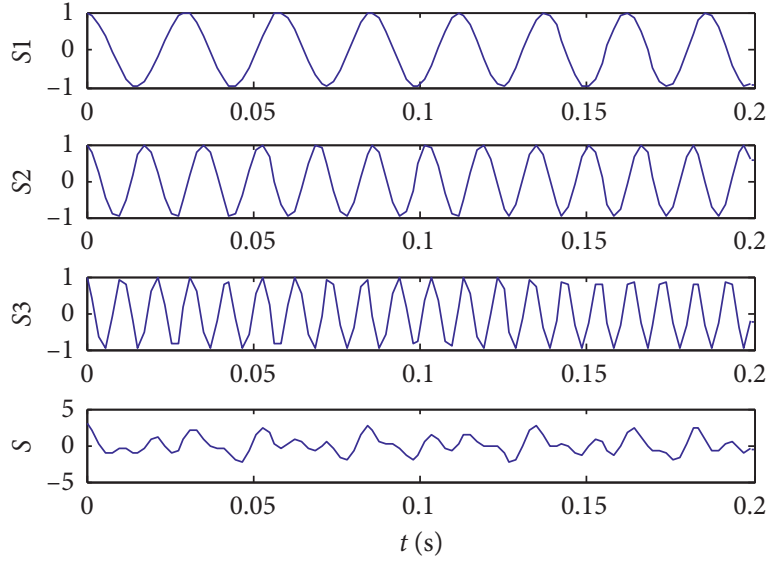

Figure 1: Time-domain waveform of the simulated signal.
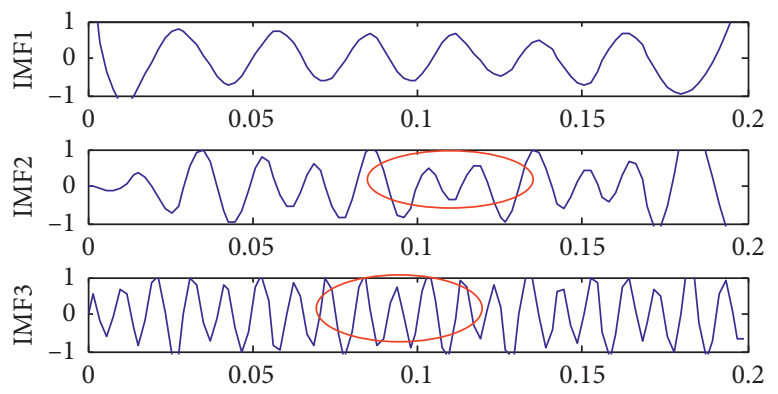

Figure 2: The calculation results by the EMD method.
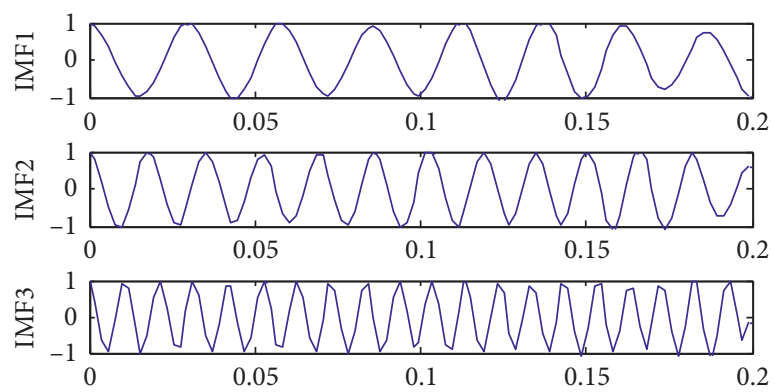

Figure 3: The calculation results by the TVF-EMD method.

TABLE 1: Quantitative index on the performance of the EMD and TVF-EMD methods.

\begin{tabular}{lcc}
\hline \multirow{2}{*}{ Original source } & \multicolumn{2}{c}{ Quantitative index } \\
& EMD $(\mathrm{dB})$ & TVF-EMD $(\mathrm{dB})$ \\
\hline S1 & 0.5324 & 17.5613 \\
S2 & 0.4042 & 14.2428 \\
S3 & 8.7849 & 18.9132 \\
Average & 3.2405 & 16.9058 \\
\hline
\end{tabular}

[33-35] proposed the robust independent component analysis (RobustICA) method. Compared with FastICA and JADE, the RobustICA method is more robust and can better extract independent components from mixed signals. 
The RobustICA method separates the independent source signals based on the kurtosis. The calculation function of kurtosis is defined as follows:

$$
\kappa(w)=\frac{E\left\{|y|^{4}\right\}-2 E^{2}\left\{|y|^{2}\right\}-\left|E\left\{|y|^{2}\right\}\right|^{2}}{E^{2}\left\{|y|^{2}\right\}},
$$

where $E\{\cdot\}$ represents the mathematical expectations.

The calculation steps of the RobustICA method are as follows:

(1) Calculate the coefficients of polynomial of optimal step size:

$$
p(\mu)=\sum_{k=0}^{4} a_{k} \mu_{k}
$$

(2) Extract the root of polynomial of optimal step size $\left\{\mu_{k}\right\}_{k=1}^{4}$.

(3) Select the root of polynomial to make the absolute value of the objective function in the search direction the largest:

$$
\mu_{\mathrm{opt}}=\arg \max _{\mu}\left|\kappa\left(w+\mu_{k} g\right)\right|
$$

(4) Update $w^{+}=w+\mu_{\text {opt }} g$.

(5) Normalize $w^{+}=w^{+} /\left\|w^{+}\right\|$.

In order to illustrate the performance, the saw-tooth signal, square signal, and sinusoidal attenuation signal are selected, and they are shown in Figure 4.

A randomly generated mixing matrix by the $\operatorname{rand}(\cdot)$ function in MATLAB software is used to mix the original simulation signals. Then the FastICA, JADE, and RobustICA methods are utilized to extract the independent components from the mixed signals. The calculation results are shown in Figure 5.

It can be seen from Figure 5 that the calculation results by RobustICA are very similar to the original simulated signals. However, the calculation results by FastICA and JADE have a certain difference with the original simulated signals, especially in the circled part. Due to the amplitude distortion in the ICA method, considering that the amplitude of the selected simulation signal is in the range of -1 to +1 , the extracted independent components are normalized. The calculated quantitative indicators are shown in Table 2.

It can be seen in Table 2 that the RobustICA provided the best recovery $x 2$ by the largest index $265.7350 \mathrm{~dB}$, which was consistent with the results in Figure 5. Although the FastICA obtained the best value of $29.5894 \mathrm{~dB}$ for $x 1$, it did not extract the $x 2$ signal very well. The second largest index value for $x 1$ is $24.2738 \mathrm{~dB}$ achieved by the JADE, but JADE does not work well for extracting $x 2$ signals. As for $x 3$, FastICA scored $-6.3843 \mathrm{~dB}$ which is lower than RobustICA and JADE. On the whole, the average score of RobustICA is $103.3583 \mathrm{~dB}$ which is much larger than that of FastICA and JADE. From the above analysis, it infers that the RobustICA method has the better performance to extract independent components than the FastICA and JADE methods.
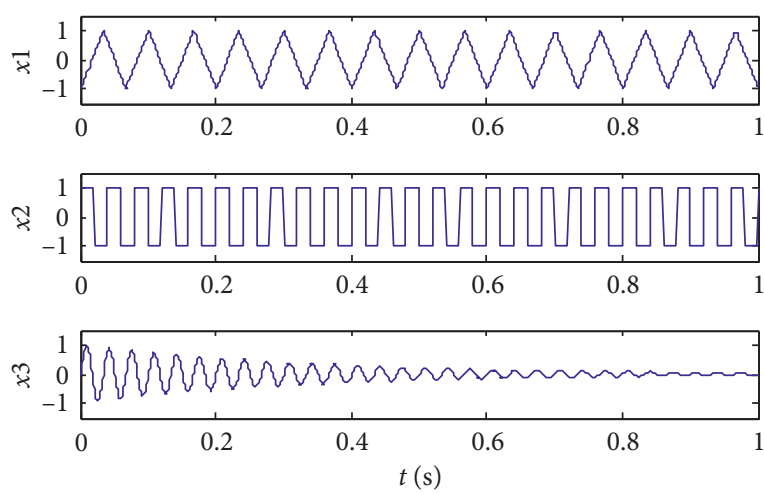

FIgURE 4: The original simulation signals.

2.3. The Single-Channel Algorithm Based on TVF-EMD and RobustICA Methods. Because the TVF-EMD method has the excellent performance for decomposing signals and the RobustICA method is a good way to extract independent components from the mixed signals, the TVF-EMD and RobustICA methods are combined together to separate noise sources. The specific calculation steps are as follows:

Step 1: in the marine engine laboratory which has a similar structural arrangement to an actual ship, the internal combustion engine noise test is carried out to obtain the single-channel noise signals.

Step 2: the TVF-EMD method is utilized to decompose the single-channel noise signal into several IMFs. By the scale selection method, the appropriate IMFs are selected and used for further calculation.

Step 3: because these selected IMFs are not always independent of each other, the IMFs and the singlechannel noise signal are combined together to form a new signal group. Then, the RobustICA method is further carried out to extract the independent components from the new signal group.

Step 4: according to the prior knowledge of the internal combustion engine and the time-frequency analysis, the combustion noise and piston slap noise are initially identified from the independent components.

Step 5: the spectral filtering method and the calculation method of piston slap noise based on the dynamic model are further carried out to identify and verify the separated results. Finally, the combustion noise and piston slap noise can be accurately obtained.

In order to illustrate the performance of the TVF-EMDRobustICA method, the simulated signal is adopted in the above equation (2). First, the mixed signal is separated by the TVF-EMD method, and the separation result is shown in Figure 3. Then, the RobustICA method is further utilized to extract independent components. Moreover, the EMDRobustICA method is also used to separate the mixed signal. The calculation results are presented in Figure 6.

From Figure 6, it can be seen that the TVF-EMDRobustICA method has achieved good results. But the EMD-RobustICA method does not work well, especially for IC1 and IC3, and they have great difference with the 

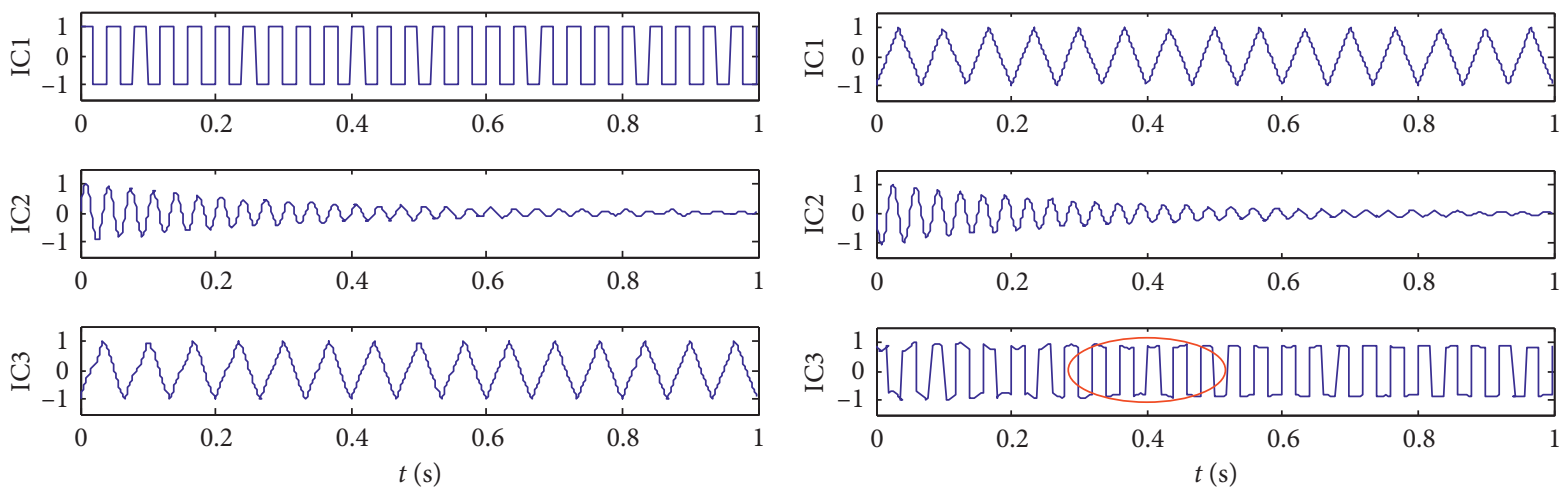

(a)

(b)
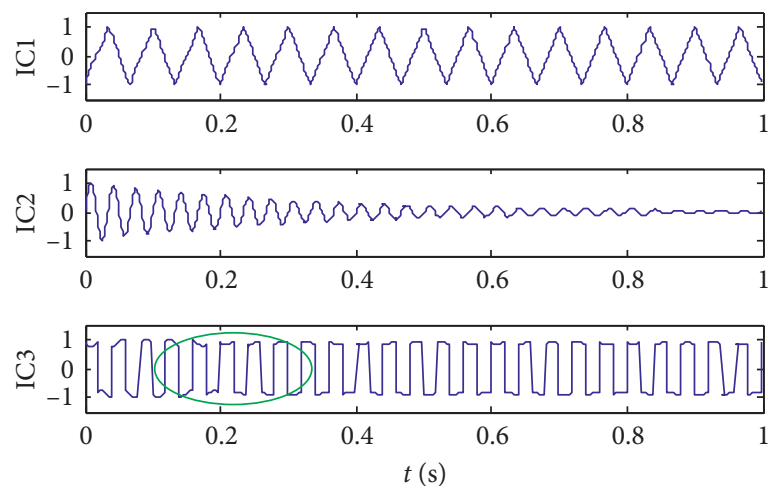

(c)

FIgure 5: The calculation results by (a) RobustICA, (b) FastICA, and (c) JADE.

TABLE 2: Quantitative index on the performance of three ICA methods.

\begin{tabular}{lccc}
\hline Original source & & Quantitative index & \\
& RobustICA $(\mathrm{dB})$ & FastICA $(\mathrm{dB})$ & 24.2738 \\
\hline$x 1$ & 21.1840 & 29.5894 & 17.0060 \\
$x 2$ & 265.7350 & 15.7141 & 26.5964 \\
$x 3$ & 23.1559 & -6.3843 & 22.6254 \\
Average & 103.3583 & 12.9731 & JADE $(\mathrm{dB})$ \\
\hline
\end{tabular}
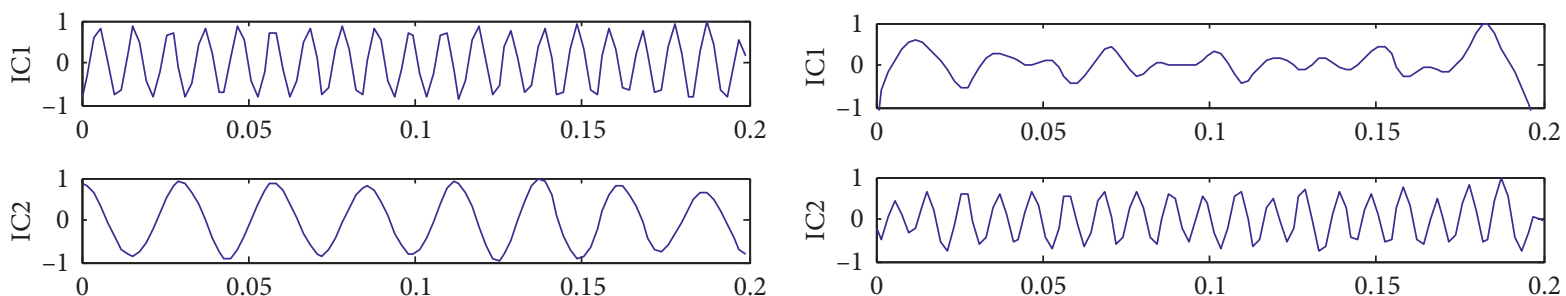

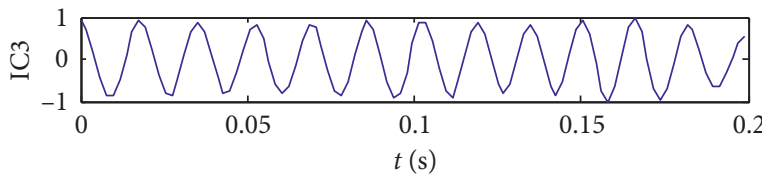

(a)

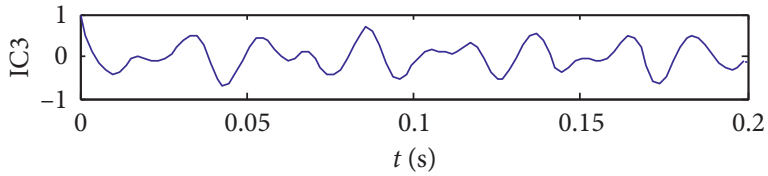

(b)

Figure 6: The calculation results by (a) TVF-EMD-RobustICA and (b) EMD-RobustICA.

original simulated $S 1$ and $S 2$. For further quantitative analysis, the calculation results of the quantitative indicators are shown in Table 3.
From Table 3, the TVF-EMD-RobustICA provided the best separated signal $S 1$ by the largest index $15.0491 \mathrm{~dB}$, and the second largest index value is $13.1466 \mathrm{~dB}$ for $S 2$. 
TABLE 3: Quantitative index on the performance of the TVF-EMDRobustICA and EMD-RobustICA methods.

\begin{tabular}{lcc}
\hline $\begin{array}{l}\text { Original } \\
\text { source }\end{array}$ & \multicolumn{2}{c}{ Quantitative index } \\
& $\begin{array}{c}\text { TVF-EMD-RobustICA } \\
(\mathrm{dB})\end{array}$ & $\begin{array}{c}\text { EMD-RobustICA } \\
(\mathrm{dB})\end{array}$ \\
\hline S1 & 15.0491 & 3.0835 \\
S2 & 13.1466 & -0.5192 \\
S3 & -5.3101 & -4.2874 \\
Average & 7.6285 & -0.5744 \\
\hline
\end{tabular}

However, the EMD-RobustICA only scored $3.0835 \mathrm{~dB}$ and $-0.5192 \mathrm{~dB}$ for $S 1$ and $S 2$, respectively. As for $S 3$, the EMDRobustICA scored $-4.2874 \mathrm{~dB}$, and it is slightly larger than the TVF-EMD-RobustICA which scored $-5.3101 \mathrm{~dB}$. In total, the average index of TVF-EMD-RobustICA is $7.6285 \mathrm{~dB}$, and the EMD-RobustICA is only $-0.5744 \mathrm{~dB}$. Thus, it infers that the TVF-EMD-RobustICA method has the better separation effect than the EMD-RobustICA method, and it is utilized to separate the noise sources of the internal combustion engine.

\section{Internal Combustion Engine Test}

3.1. Test Platform. The internal combustion engine test was carried out in the marine engine laboratory which has a similar structural arrangement to the actual ship, and it is shown in Figure 7.

In the marine engine laboratory, there is a MAN B\&W 6L16/24-type diesel engine. The main technical parameters are shown in Table 4.

When the internal combustion engine is running, the six cylinders will generate lots of noise. It is very difficult to directly separate the noise sources generated by the six cylinders. In fact, each cylinder of the internal combustion engine produces the similar noise source. Therefore, it is only necessary to study the noise source generated by one specified cylinder. Hence, it is necessary to isolate the interference noise generated by other five cylinders.

3.2. Lead Coverage Method. In this experiment, the lead coverage method is adopted to wrap five cylinders (No. 1 cylinder, No. 2 cylinder, No. 3 cylinder, No. 5 cylinder, and No. 6 cylinder) of the internal combustion engine, and only No. 4 cylinder is not wrapped. In the process of the lead coverage method, firstly, the $10 \mathrm{~mm}$ thick flame retardant sound insulation cotton is wrapped outside the internal combustion engine. Secondly, the $1.5 \mathrm{~mm}$ thick lead plate is wrapped outside the internal combustion engine. Finally, the $10 \mathrm{~mm}$ thick flame retardant sound insulation cotton is again wrapped outside the internal combustion engine. The three-layer coverage method is adopted to isolate the interference noise. The lead coverage method is shown in Figure 8.

Through the lead coverage method, the interference noise generated by other five cylinders can effectively be isolated. It is beneficial to the noise source separation of the designated cylinder.

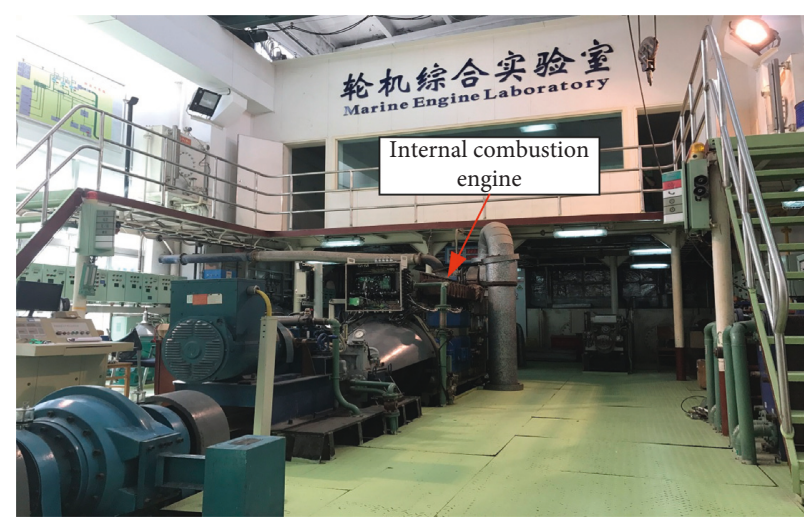

FIGURE 7: Marine engine laboratory.

TABLE 4: The main technical parameters of the internal combustion engine.

\begin{tabular}{lc}
\hline Parameters & Parameter values \\
\hline Number of cylinders & 6 \\
Number of strokes & 4 \\
Cooling system & Water cooled \\
Cylinder diameter & $160 \mathrm{~mm}$ \\
Stroke & $240 \mathrm{~mm}$ \\
Fire order & $1-2-4-6-5-3$ \\
Compression ratio & $15.2: 1$ \\
Rated power & $540 \mathrm{~kW}$ \\
Dimensions & $2627 \mathrm{~mm} \times 760 \mathrm{~mm} \times 1866 \mathrm{~mm}$ \\
\hline
\end{tabular}

3.3. Measuring System and Measuring Points. Through the lead coverage method, the interference noise produced by other five cylinders can be isolated as much as possible. Then as for No. 4 cylinder, the microphones are utilized to measure the noise signals at the cylinder head top, the main slap side, and the vice slap side. The specific location of noise measurement points are shown in Figure 9.

The internal combustion engine measurement system consists of sensor equipment (sound pressure sensor, cylinder pressure sensor, charge amplifier, and top dead center sensor), NI cDAQ 9172 data acquisition chassis, NI 9234 data acquisition card, computer, etc., and it is shown in Figure 10.

The type of the cylinder pressure sensor is 6013CA, in which the range is 250 bar and the sensitivity is $21 \mathrm{pC} / \mathrm{bar}$. The type of the single-channel charge amplifier is 5018A1000. The PCB130F20 microphones are calibrated before measurement. The noise data measured in the test are saved on the computer through LabVIEW integrated data acquisition system. The sampling frequency is $25600 \mathrm{~Hz}$.

The rated speed of MAN B\&W 6L16/24-type diesel engine is $1000 \mathrm{rpm}$. Thus, the test condition is selected as $1000 \mathrm{rpm}$ and no-load condition. Through the internal combustion engine test, the cylinder pressure signal $p$ and each side noise signals (the cylinder head top $y 1$, the main slap side $y 2$ and the vice slap side $y 3$ ) of a working cycle of the internal combustion engine can be obtained, and it is shown in Figure 11. 


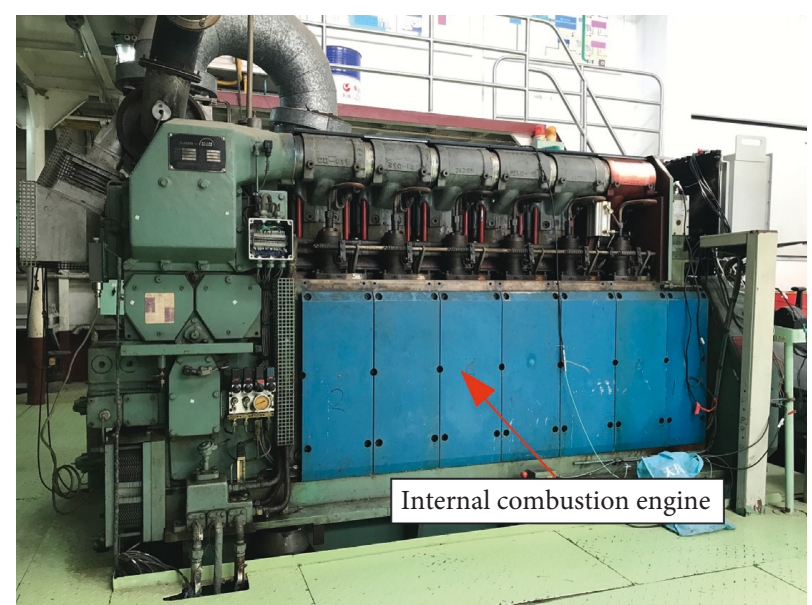

(a)

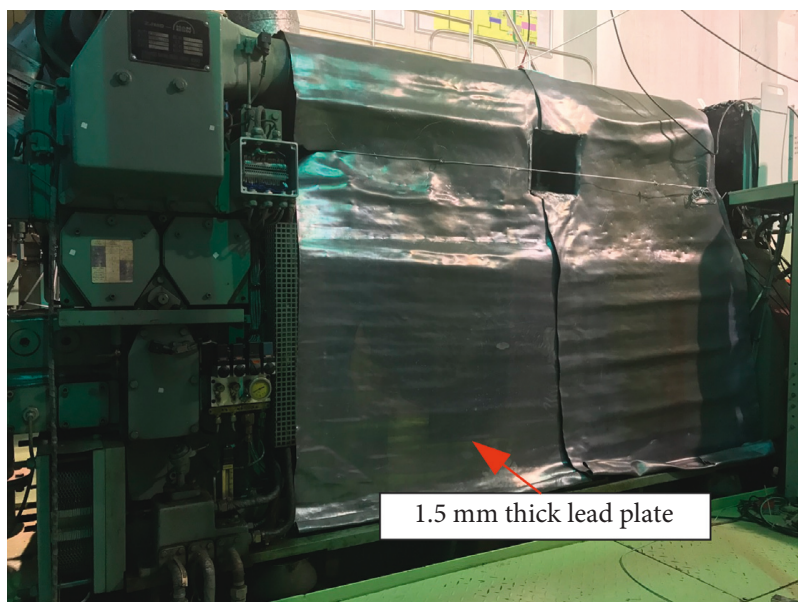

(c)

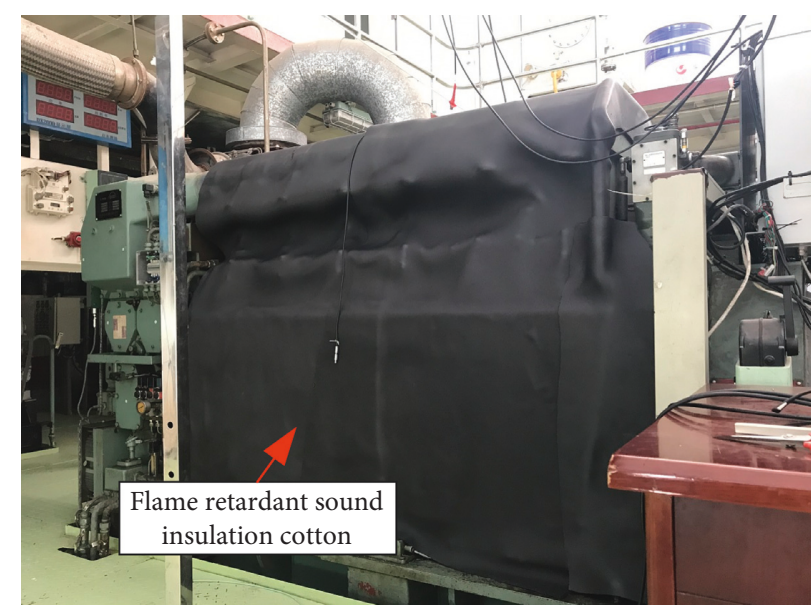

(b)

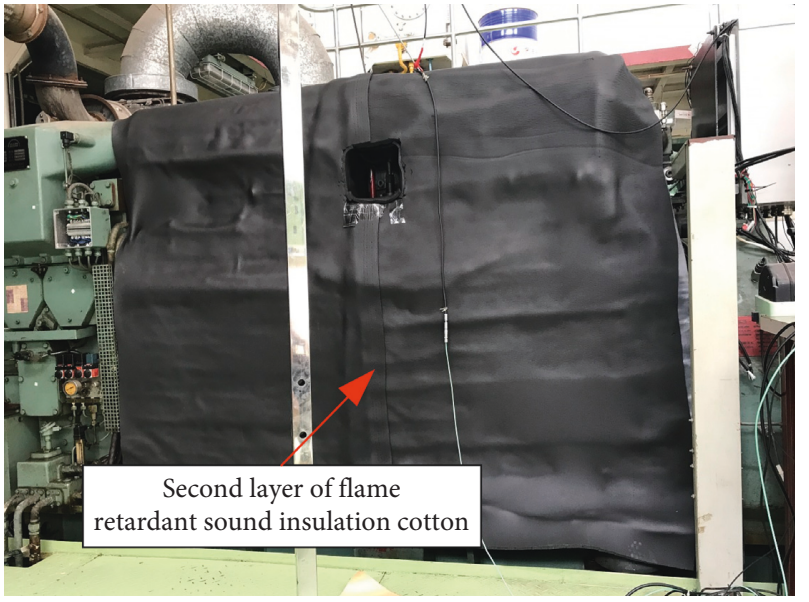

(d)

FIGURE 8: The lead coverage method. (a) Diesel engine. (b) The first layer of flame retardant sound insulation cotton. (c) The $1.5 \mathrm{~mm}$ thick lead plate. (d) The second layer of flame retardant sound insulation cotton.

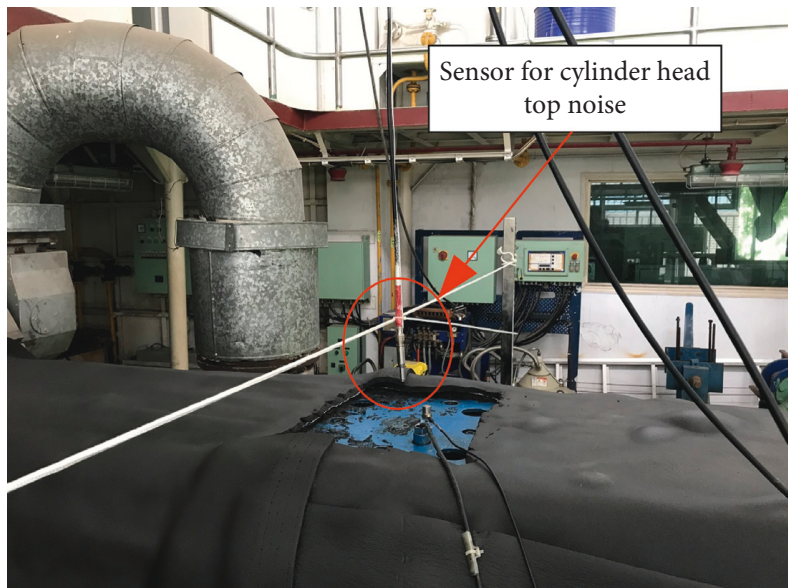

(a)

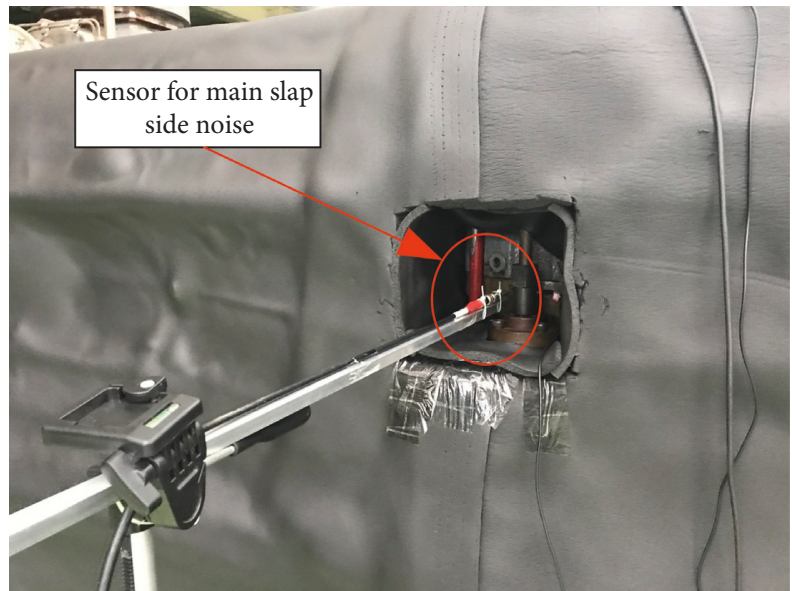

(b)

Figure 9: Continued. 


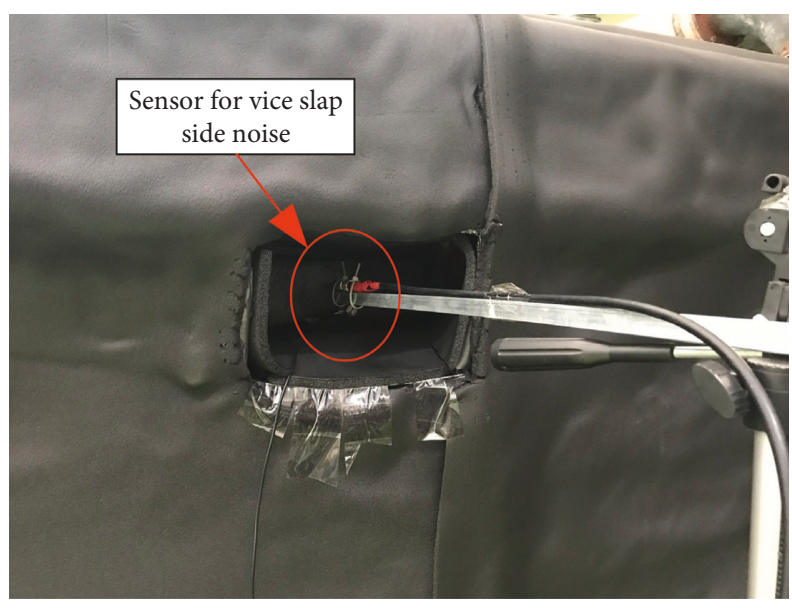

(c)

Figure 9: Specific location of noise measurement points. At (a) the cylinder head top, (b) the main slap side, and (c) the vice slap side.

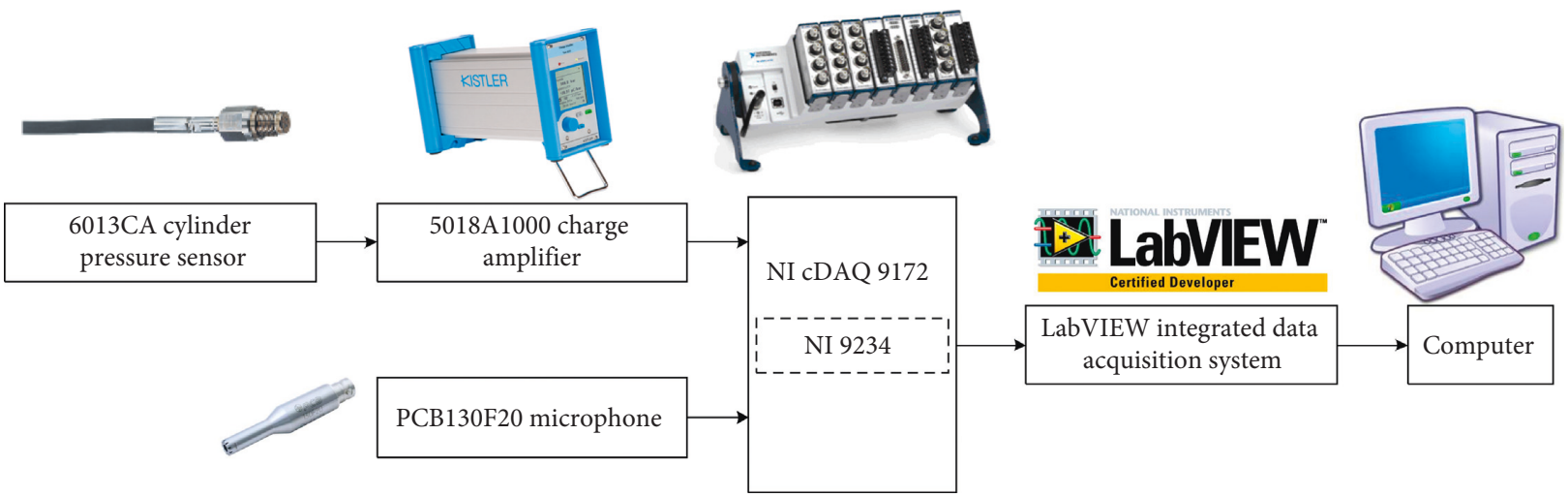

FIgURE 10: The internal combustion engine measurement system.

\section{Separation and Identification of Noise Sources}

Through the internal combustion engine test, each side noise signals can be obtained. Firstly, the TVF-EMD method is applied to decompose the cylinder head top noise signal $y 1$ into several IMFs. The decomposition results are shown in Figure 12.

Through the TVF-EMD method, nine IMFs can be obtained. The scale selection method is utilized to select the IMFs which have the high coherence with noise source of the internal combustion engine for further calculation. The calculation expression of the correlation coefficient is shown in the following equation [15]:

$$
r=\frac{\sum_{i=1}^{n}\left(x_{i}-\bar{x}\right)\left(y_{i}-\bar{y}\right)}{\sqrt{\sum_{i=1}^{n}\left(x_{i}-\bar{x}\right)^{2} \sum_{i=1}^{n}\left(y_{i}-\bar{y}\right)^{2}}}
$$

where $\bar{x}$ and $\bar{y}$ are, respectively, the mean of signal $x$ and signal $y$.

Through calculation, the correlation coefficient between each IMF and noise signal is shown in Table 5.

Considering that the internal combustion engine has many noise sources, in order to retain more components
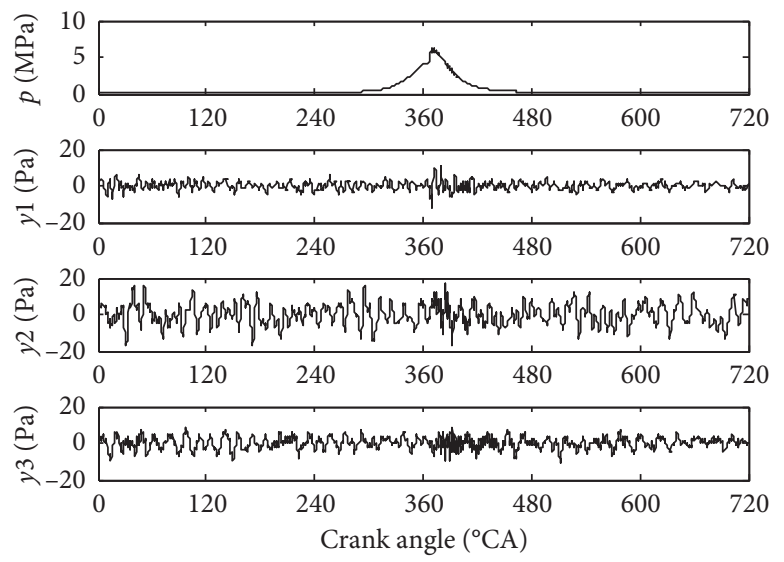

FIGURE 11: Cylinder pressure signal and each side noise signals of a working cycle of the internal combustion engine.

for the next calculation, the components whose correlation coefficient is less than 0.1 are removed. The IMF3 IMF9 are retained for subsequent calculation. However, these IMFs are not always independent of each other. Therefore, it is needed to further extract the independent component from these IMFs. These IMFs and the original cylinder 


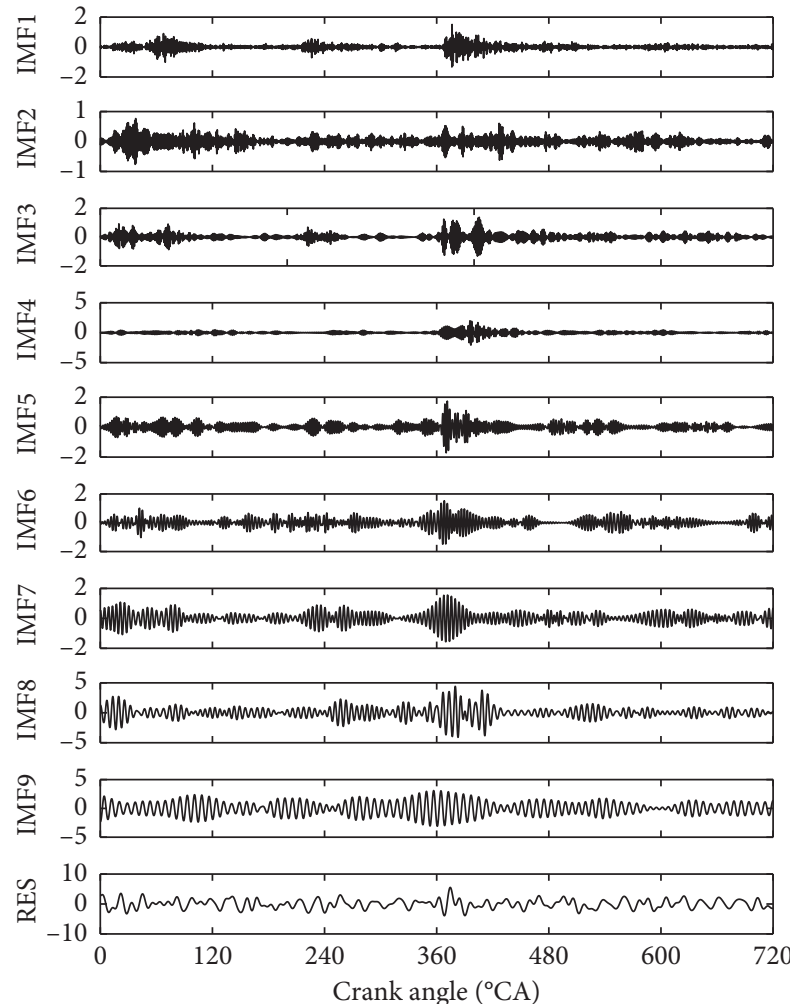

FIgURE 12: The decomposition results by the TVF-EMD method.

head top noise signals are combined together to form a new signal group. Then, the RobustICA method is further employed to extract the independent component from the new signal group. The calculation results are shown in Figure 13.

From Figure 13, each independent component may be correspond to the internal combustion engine noise source, such as combustion noise, piston slap noise, air valve knock noise, fuel injection pump noise, gear meshing noise, and so forth. The main goal of this paper is to study combustion noise and piston slap noise. As for the other noise sources, it needs to be further researched.

According to the prior knowledge of the internal combustion engine, the IC1 and IC2 may be the combustion noise and the piston slap noise. The time-domain waveform, spectrum, and time-frequency diagram of IC1 and IC2 are shown in Figure 14.

From Figure 14(a), firstly, from the perspective of the time domain, the time-domain waveform amplitude of IC1 varies greatly at $370^{\circ} \mathrm{CA}$. According to the relevant prior knowledge of the internal combustion engine, the firing order of the internal combustion engine is 1-2-4-6-5-3. In the test, the firing angle of No. 4 cylinder is about $370^{\circ} \mathrm{CA}$. Thus, the change time of IC1 amplitude is consistent with the firing time of No. 4 cylinder. Secondly, from the perspective of the frequency domain, the frequency component of IC1 is concentrated around $3,000 \mathrm{~Hz}$. When combustion occurs in No. 4 cylinder, high-frequency oscillation occurs due to combustion, resulting in a higher frequency component. In addition, as can be seen from the time-frequency diagram of IC1, the frequency component
TABle 5: The correlation coefficient.

\begin{tabular}{lc}
\hline IMFs & Correlation coefficient \\
\hline IMF1 & 0.0787 \\
IMF2 & 0.0676 \\
IMF3 & 0.1034 \\
IMF4 & 0.1225 \\
IMF5 & 0.1227 \\
IMF6 & 0.1426 \\
IMF7 & 0.1741 \\
IMF8 & 0.4235 \\
IMF9 & 0.5181 \\
\hline
\end{tabular}

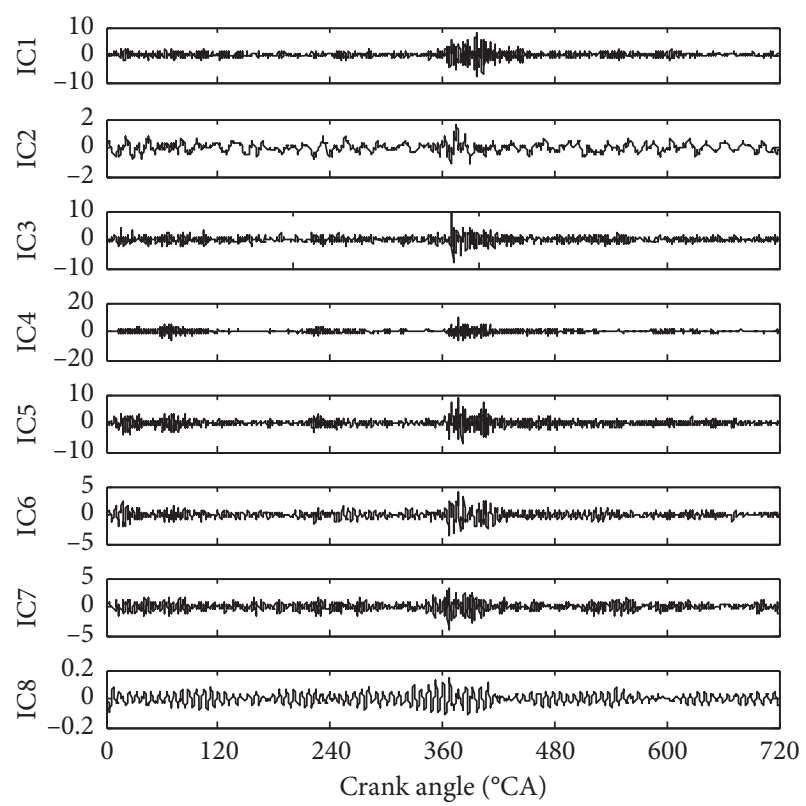

FIgURE 13: The calculation results by the RobustICA method.

energy at about $370^{\circ} \mathrm{CA}$ and $3,000 \mathrm{~Hz}$ is the highest. It coincides with the moment when No. 4 cylinder burns and the high-frequency oscillation is caused by combustion. Thus, it can be considered that IC1 is the combustion noise.

From Figure 14(b), from the perspective of the time domain, the time-domain waveform amplitude of IC2 varies greatly at $370^{\circ} \mathrm{CA}$. It coincides with the moment when the piston of No. 4 cylinder hits the cylinder wall. From the perspective of the frequency domain, the frequency component of IC2 is concentrated around $400 \mathrm{~Hz}$. Usually the frequency of piston slap noise is low. From the time-frequency diagram, at round $370^{\circ} \mathrm{CA}$ and $400 \mathrm{~Hz}$, the frequency component energy is large. Thus, it can be considered that the IC2 is the piston slap noise.

Similarly, as for the main slap side noise signal $y 2$ and the vice slap side noise signal $y 3$, the calculation results are shown in Figures 15 and 16, respectively.

From Figure 15(a), the moment of amplitude change of IC1 and the ignition time of No. 4 cylinder are both at $370^{\circ} \mathrm{CA}$. The frequency of IC1 is concentrated around $3,000 \mathrm{~Hz}$. In the time-frequency diagram, the frequency component energy is large at round $370^{\circ} \mathrm{CA}$ and $3,000 \mathrm{~Hz}$. 

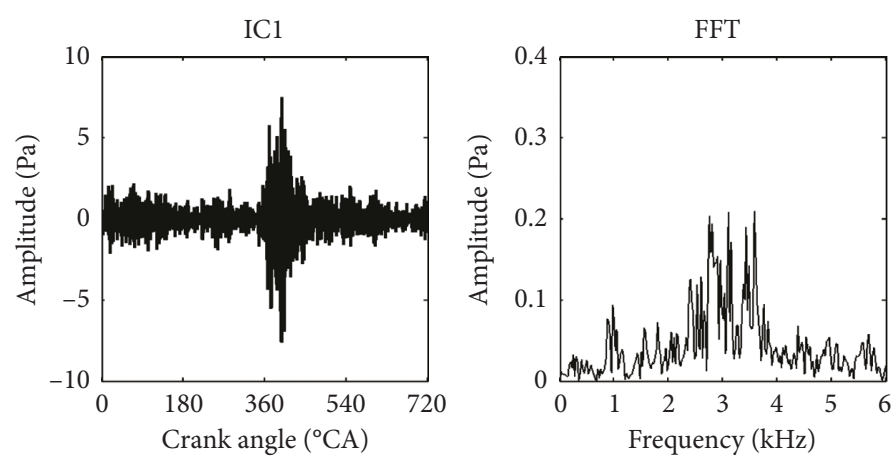

(a)

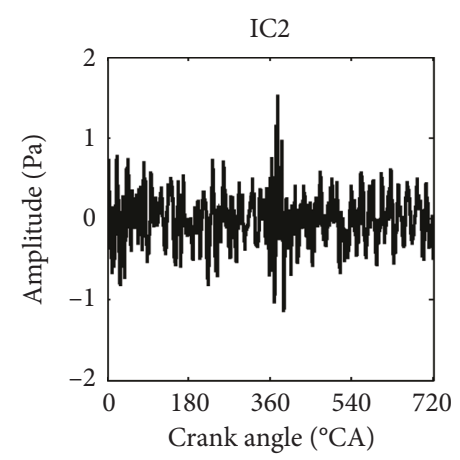

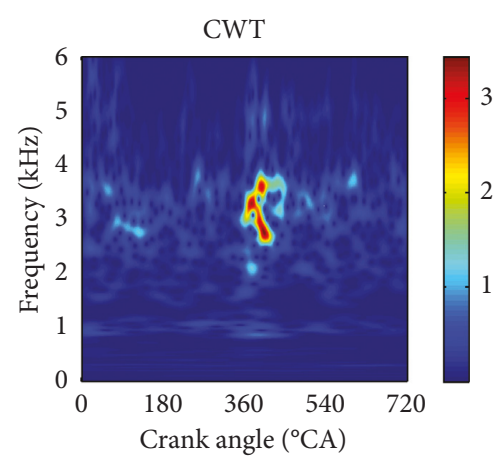

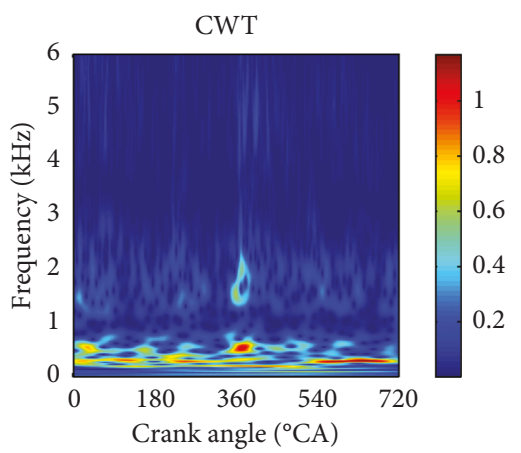

(b)

FIgURE 14: Time-domain waveform, spectrum, and time-frequency diagram of (a) IC1 and (b) IC2 from cylinder head top noise signal $y 1$.
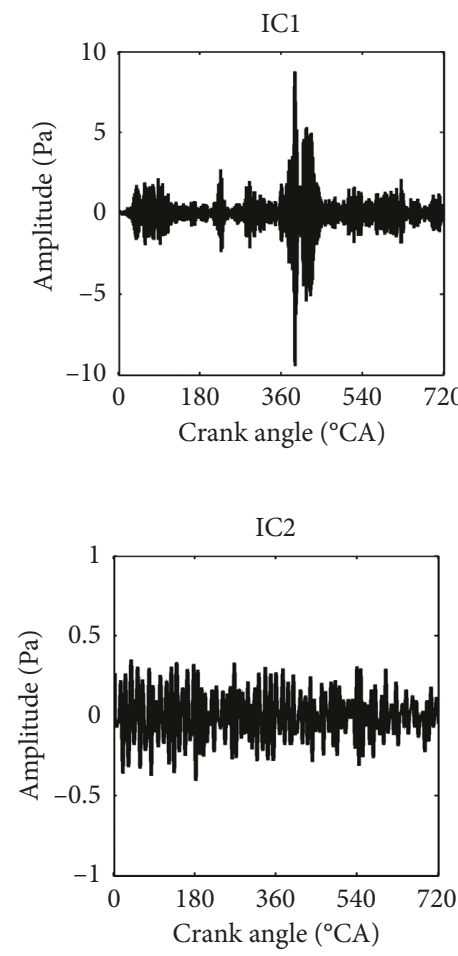

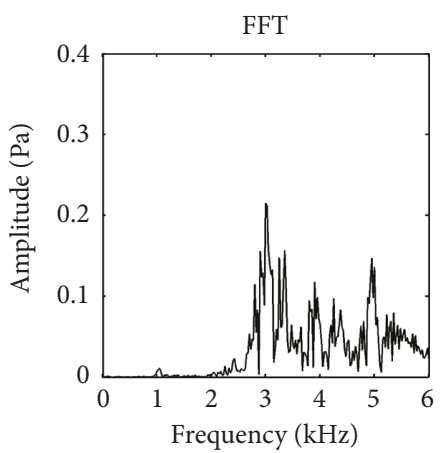

(a)

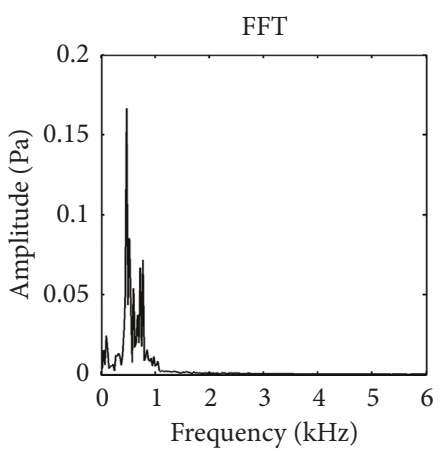

(b)

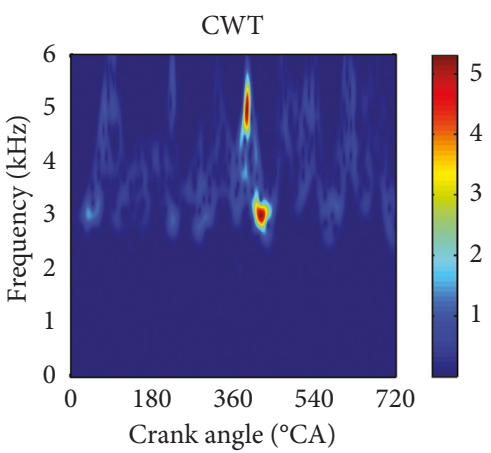

CWT

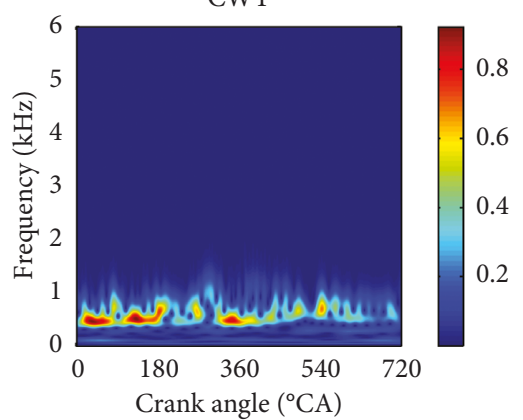

FIgURE 15: Time-domain waveform, spectrum, and time-frequency diagram of (a) IC1 and (b) IC2 from main slap side noise signal $y 2$.

However, there is still a certain frequency component at around $5,000 \mathrm{~Hz}$. The noise measurement position is at main slap side, and there is an injection pump next to the main slap side. The 5,000 Hz frequency component may be caused by the injection pump. The main component of IC1 is the combustion noise. From Figure 15(b), the frequency 

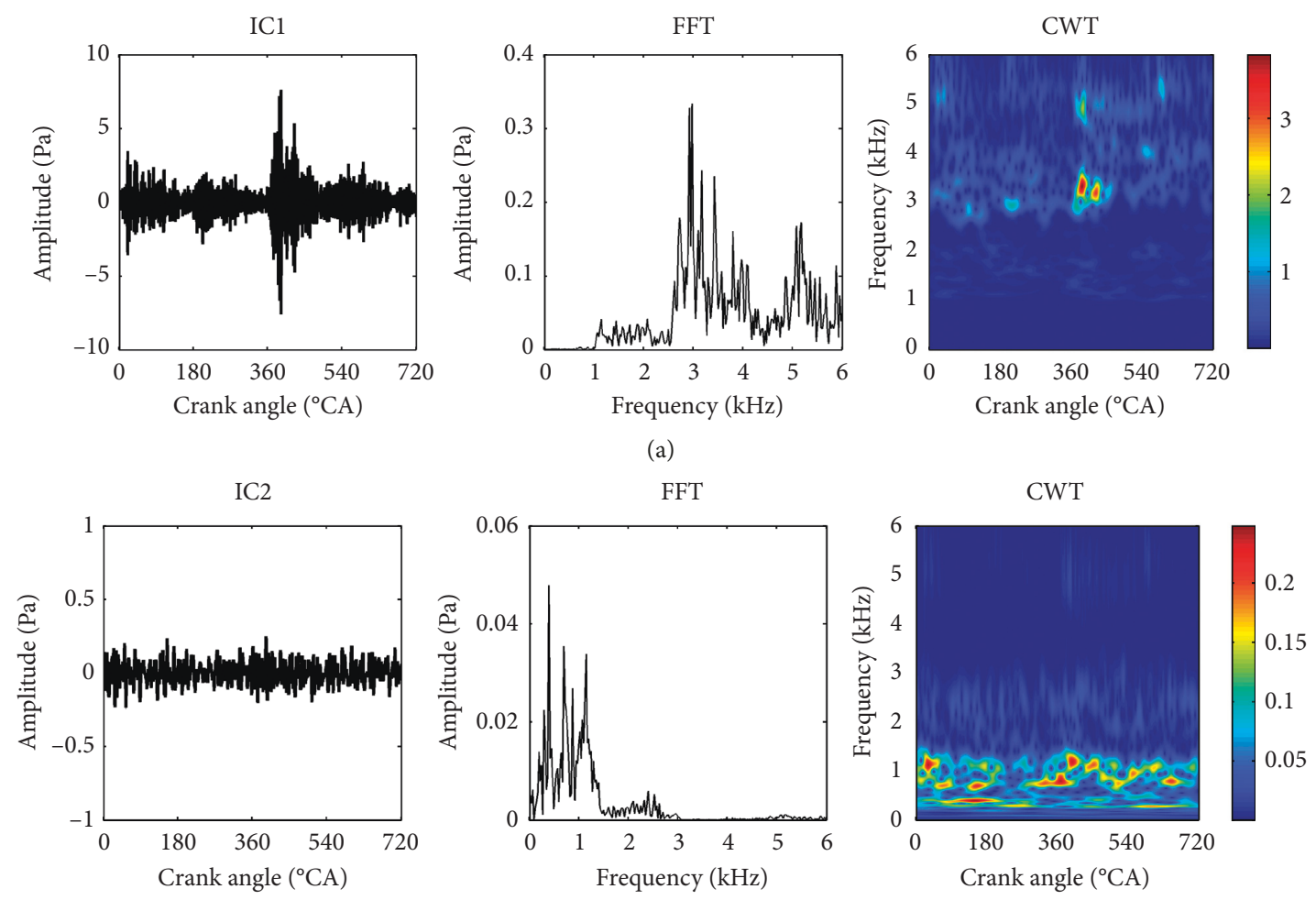

(b)

FIGURE 16: Time-domain waveform, spectrum, and time-frequency diagram of (a) IC1 and (b) IC2 from vice slap side noise signal $y 3$.

component of IC2 is mainly concentrated around $400 \mathrm{~Hz}$. In the time-frequency diagram, the frequency component energy is large at around $370^{\circ} \mathrm{CA}$ and $400 \mathrm{~Hz}$. But the frequency component energy also appears at other locations. The piston has a certain contact area with the inner wall of the cylinder liner. This may be caused by repeated collisions between the piston and the cylinder liner. Thus, it can be considered that the IC2 component is mainly the piston slap noise.

From Figure 16(a), the moment of amplitude change of IC1 and the ignition time of No. 4 cylinder are also both at $370^{\circ} \mathrm{CA}$. The frequency component of IC1 is also concentrated around $3,000 \mathrm{~Hz}$. When No. 4 cylinder burns at around $370^{\circ} \mathrm{CA}$, it produces high-frequency oscillation components. Thus, it can be considered that the IC1 is mainly the combustion noise. From Figure 16(b), the frequency component of IC2 is mainly concentrated around $400 \mathrm{~Hz}$. In the time-frequency diagram, the frequency component energy is large at around $370^{\circ} \mathrm{CA}$ and $400 \mathrm{~Hz}$. But it also has some other frequency components around $1,000 \mathrm{~Hz}$. Near the vice slap side, there are some other parts such as exhaust pipe, and the frequency component may be caused by them. Therefore, the main component of IC2 is the piston slap noise.

\section{Evaluation and Discussion}

In order to further evaluate the separation effect of the separated combustion noise and piston slap noise, the spectral filtering method [11] and the calculation method of piston slap noise based on the dynamic model [36-39] are further utilized to calculate the independent combustion noise and piston slap noise, respectively.

5.1. Spectral Filtering Method. The MAN B\&W 6L16/24type internal combustion engine has six cylinders. Suppose the cylinder pressure of these six cylinders is $P_{k}(t), k \in$ $[1, \ldots, 6]$. The combustion noise generated by these six cylinders is $C_{k}(t), k \in[1, \ldots, 6]$. The transfer function between cylinder pressure and combustion noise is $H_{k}(t)$, $k \in[1, \ldots, 6]$. The combustion noise calculation model is shown in Figure 17.

From Figure 17, the combustion noise can be calculated as follows:

$$
C_{k}(t)=P_{k}(t) * H_{k}(t), \quad k \in[1, \ldots, 6] .
$$

The total combustion noise of the internal combustion engine is the sum of combustion noise generated by the six cylinders:

$$
C(t)=\sum_{k=1}^{6} C_{k}(t) .
$$

However, in the test, the five cylinders of the internal combustion engine were wrapped by the lead coverage method, and only No. 4 cylinder was exposed. Therefore, this combustion noise calculation model becomes a single-cylinder combustion noise calculation model, and it is shown in Figure 18. 


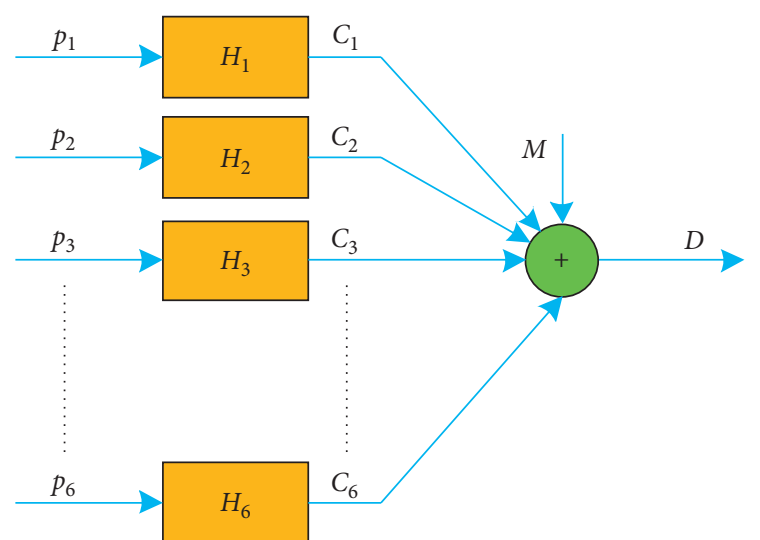

FIGURE 17: The combustion noise calculation model.

Assume that the cylinder pressure and combustion noise of No. 4 cylinder are $P(t)$ and $C(t)$. The radiation noise signal of No. 4 cylinder is $D(t)$. The other interference noise signal is $M(t)$ :

$$
\begin{aligned}
& D(t)=C(t)+M(t), \\
& C(t)=P(t) * H(t) .
\end{aligned}
$$

In the single-cylinder combustion noise calculation model, the cylinder pressure $P(t)$ and the radiation noise signal $D(t)$ can directly be obtained by the test. Firstly, the spectral filtering function $W(t)$ is needed to be calculated:

$$
\begin{aligned}
& W(f)=\frac{S_{\mathrm{PD}}(f)}{S_{\mathrm{PP}}(f)}=\frac{\langle\bar{P}(f) D(f)\rangle}{\langle\bar{P}(f) P(f)\rangle}, \\
& W(t)=\mathrm{FT}^{-1}\{W(f)\},
\end{aligned}
$$

where $S_{\mathrm{PD}}(f)$ is the cross-spectrum of cylinder pressure $P(t)$ and radiation noise signal $D(t) . S_{\mathrm{PP}}(f)$ is the autospectrum of cylinder pressure $P(t)$ and radiation noise signal $D(t)$.

After calculating the spectral filtering function $W(t)$, the combustion noise estimation signal $\widetilde{C}(t)$ can be obtained through convolution the spectral filtering function $W(t)$ with the cylinder pressure signal $P(t)$ :

$$
\widetilde{C}(t)=P(t) * W(t),
$$

where $*$ represents the convolution operation.

The error $E(t)$ between the actual combustion noise signal $C(t)$ and the combustion noise estimation signal $\widetilde{C}(t)$ is calculated as follows:

$$
E(t)=C(t)-\widetilde{C}(t)
$$

The combustion noise signal can be calculated by the spectral filtering method. However, there is an error between the calculated combustion noise and the actual combustion noise. In this paper, the calculated combustion noise by the spectral filtering method is mainly utilized to evaluate the separated combustion noise. Although there is an error between the calculated combustion noise and the actual combustion noise, the calculated combustion noise has the main characteristics

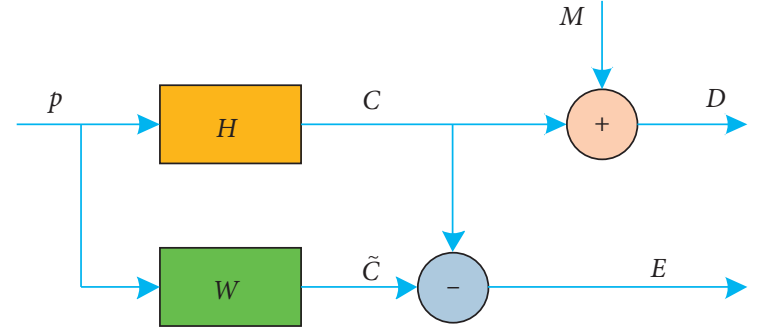

Figure 18: Single-cylinder combustion noise calculation model.

of the actual combustion noise. Thus, the calculated combustion noise can be used to evaluate the separated combustion noise. As for the error, it needs to be further researched.

The combustion noise estimation signal can be calculated through the spectral filtering method. Then, the calculated combustion noise estimation signal is compared with the separated combustion noise. The calculated results are shown in Figure 19.

From Figure 19, at the cylinder head top, the separated combustion noise is consistent with the calculated combustion noise by the spectral filtering method. But it has many other interference components in the separated combustion noise. This is because the cylinder head top receives interference noise from both main slap side and vice slap side. But its main component is combustion noise. At main slap side, the separated combustion noise is basically consistent with the calculated combustion noise by the spectral filtering method, but there is a small difference in the vicinity of $2,000 \mathrm{~Hz}$. At vice slap side, the separated combustion noise is also basically consistent with the calculated combustion noise, but there is a small difference in the vicinity of $5,000 \mathrm{~Hz}$. In general, the frequency characteristics of the separated combustion noise are consistent with the calculated combustion noise by the spectral filtering method. Thus, it can be considered that the combustion noise can accurately be obtained by using the proposed single-channel algorithm. The frequency component of combustion noise is concentrated around $3,000 \mathrm{~Hz}$.

5.2. Calculation Method of Piston Slap Noise Based on Dynamic Model. The piston hits the cylinder wall to generate piston slap noise. When the internal combustion engine is working, the movement of the piston in the cylinder liner is very complicated, including the main (axial reciprocating) motion and the secondary (lateral and tilting) motion. The dynamic model of the piston in the cylinder liner is shown in Figure 20.

The schematic diagram of the force of the piston in the cylinder liner is shown in Figure 21.

In Figure 21, $F_{\mathrm{G}}$ is the thrust of the cylinder pressure generated in the in-cylinder combustion on the top surface of the piston. $\widetilde{F}_{\text {IC }}$ and $\widetilde{F}_{\text {IP }}$ are, respectively, the piston inertia force and the piston pin inertia force generated by the reciprocating movement of the piston. $F_{\mathrm{IC}}, F_{\mathrm{IP}}$, and $M_{\text {IC }}$ are, respectively, the inertial force of the piston, the 


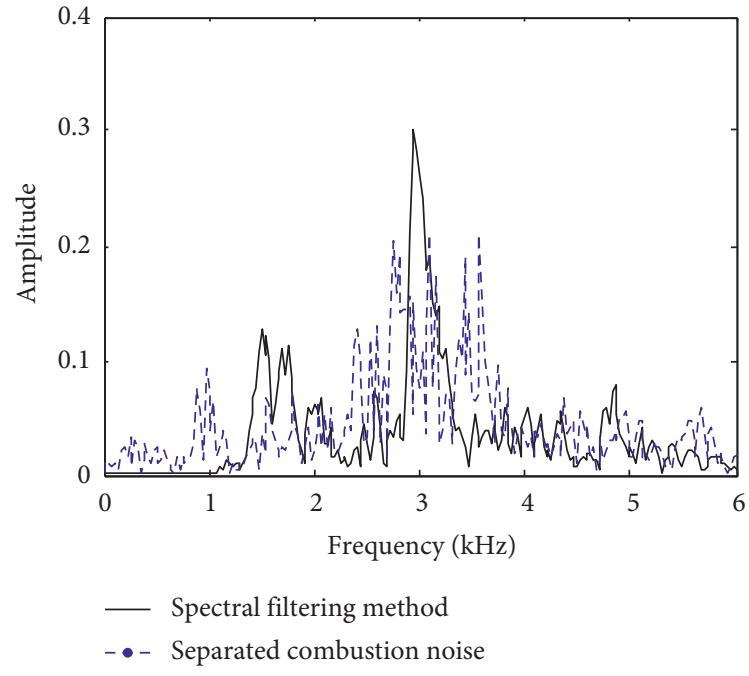

(a)

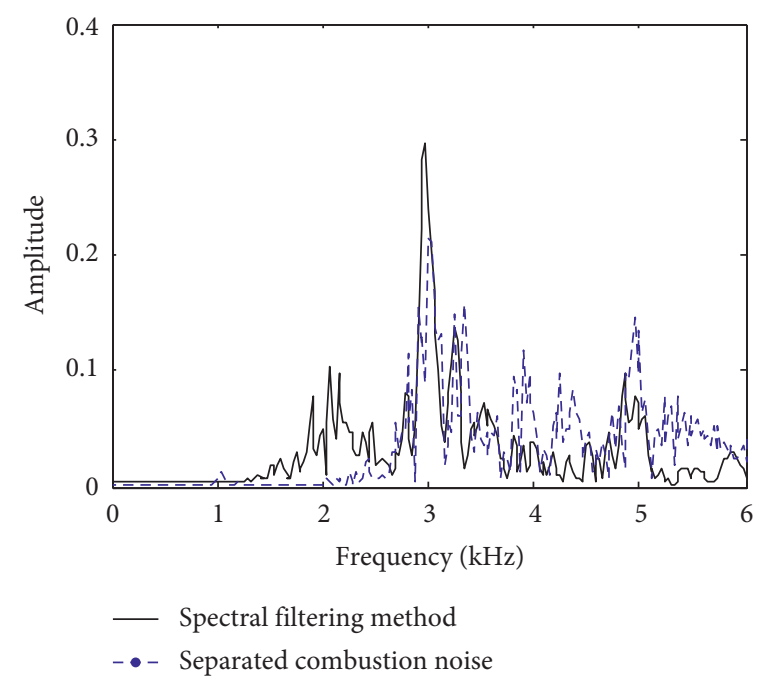

(b)

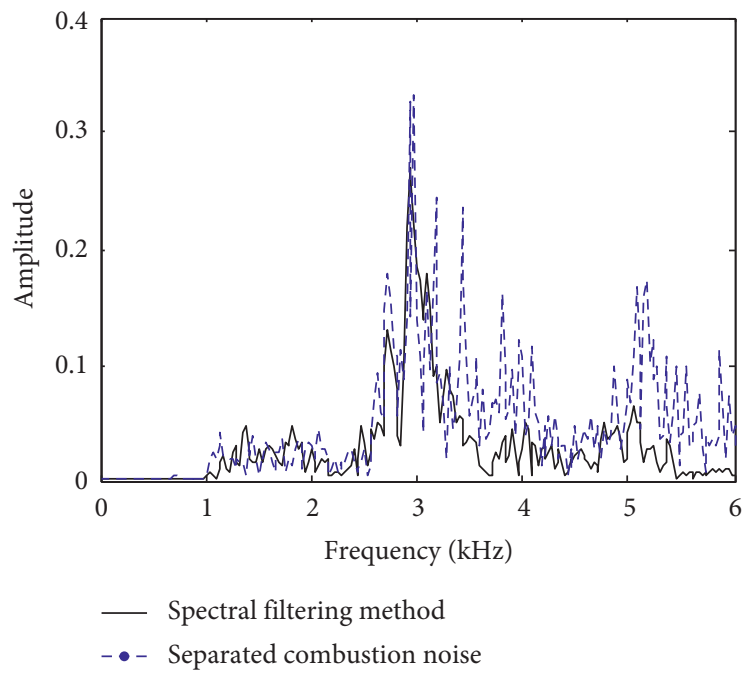

(c)

FIGURE 19: The compared results between the calculated combustion noise and the separated combustion noise. At (a) cylinder head top, (b) main slap side, and (c) vice slap side.

inertial force of the piston pin, and the inertial moment of the piston produced by the second-order motion of the piston. $F_{\text {hyd }}$ and $M_{\text {hyd }}$ are, respectively, the lubricating force and lubricating torque acting on the piston skirt. $F_{\mathrm{f}}$ and $M_{\mathrm{f}}$ are, respectively, the viscous friction of the lubricating oil and the frictional moment generated by the piston skirt. $F$ is the force of the connecting rod. $d_{\mathrm{COG}}$ is the distance between the center of the piston pin and the centerline of the piston. $a$ and $b$ are, respectively, the the distance between the center of mass of the piston pin and the upper part of the piston skirt and the distance between the center of mass of the piston and the upper part of the piston skirt. $\phi$ is the angle between the connecting rod, and the axis of the piston.

According to the force of the piston in the cylinder liner, the dynamic equation of piston movement in the cylinder liner can be obtained:

$$
\begin{aligned}
& {\left[\begin{array}{cc}
m_{\text {pin }}\left(1-\frac{a}{L}\right)+m_{\text {pis }}\left(1-\frac{b}{L}\right) & m_{\text {pin }} \frac{a}{L}+m_{\text {pis }} \frac{b}{L} \\
\frac{I_{\text {pis }}}{L}+m_{\text {pis }}(a-b)\left(1-\frac{b}{L}\right) & m_{\text {pis }}(a-b) \frac{b}{L}-\frac{I_{\text {pis }}}{L}
\end{array}\right]\left[\begin{array}{c}
\ddot{e}_{t} \\
\ddot{e}_{b}
\end{array}\right]} \\
& =\left[\begin{array}{c}
F_{\text {hyd }}+F_{\mathrm{S}}+F_{\mathrm{f}} \tan \phi \\
M_{\text {hyd }}+M_{\mathrm{S}}+M_{\mathrm{f}}
\end{array}\right] .
\end{aligned}
$$

In fact, there is a lubricant film between the piston and the cylinder liner. Therefore, it is also necessary to consider the effect of lubricant film on the movement of the piston in the cylinder liner. The Reynolds equation for the effect of lubricant film is defined as follows: 


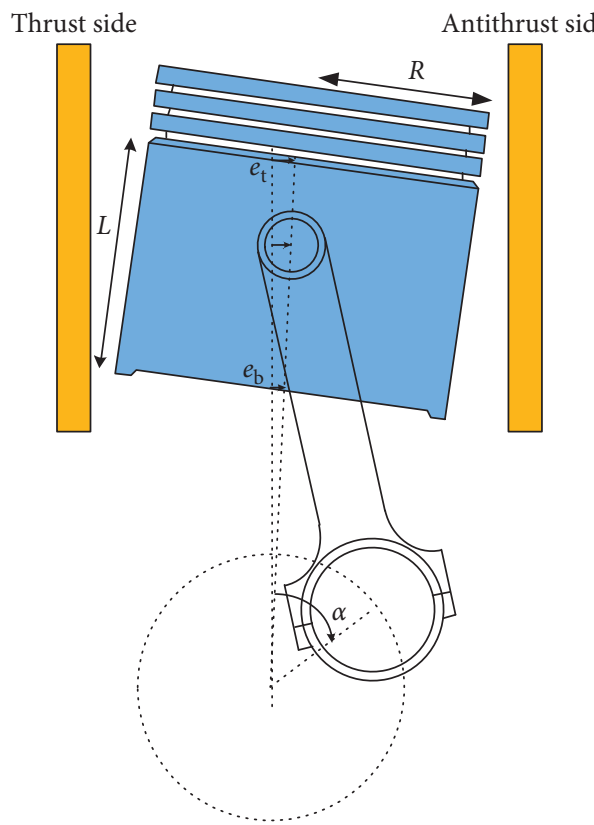

Figure 20: The dynamic model of the piston.

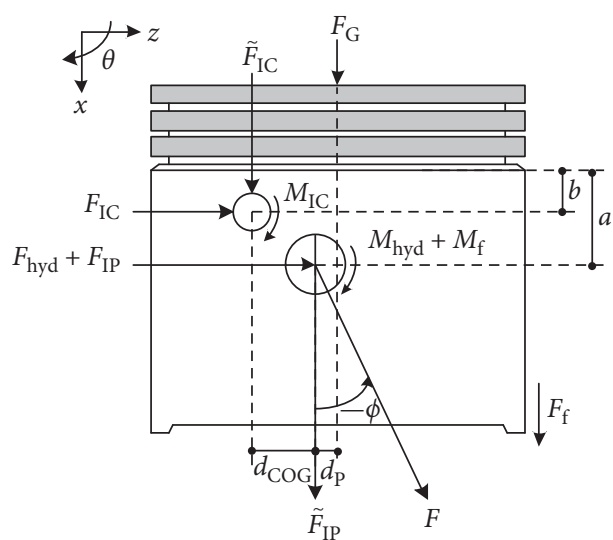

Figure 21: The force of the piston in the cylinder liner.

$$
\begin{aligned}
\frac{\partial}{\partial x}\left(\frac{\rho h^{3}}{\eta} \frac{\partial p}{\partial x}\right)+\frac{\partial}{\partial y}\left(\frac{\rho h^{3}}{\eta} \frac{\partial p}{\partial y}\right)= & 6 u \frac{\partial(\rho h)}{\partial x}+6 V \frac{\partial(\rho h)}{\partial y} \\
& +12 \frac{\partial(\rho h)}{\partial t}
\end{aligned}
$$

where $x$ is the circumferential direction of the piston liner, $y$ is the axial direction along the liner, $V$ is the reciprocating speed of the piston, $\eta$ is the viscosity of lubricating oil, $t$ is the time, $p$ is the lubricating oil film pressure, $h$ is the thickness of the lubricant film, and $\rho$ is the lubricating oil density.

Through formulas (15) and (16), the lubricant film pressure and the piston second-order motion displacement, velocity, and acceleration can be obtained.

The piston collides with the inner wall of the cylinder liner to generate piston slap noise, and it will attenuate through the body structure. Therefore, it is necessary to calculate the attenuation factor of sound propagation of the body structure:

$$
\eta_{\mathrm{a} / \mathrm{v}}=\frac{W_{\mathrm{a}}}{W_{\mathrm{v}}},
$$

where $W_{\mathrm{a}}$ is the surface acoustic power of the body and $W_{\mathrm{v}}$ is the piston and liner inner wall collision sound power.

The formula for calculating the body surface acoustic power $W_{\mathrm{a}}$ is defined as follows:

$$
W_{\mathrm{a}}=\sigma \rho_{\mathrm{a}} c_{\mathrm{a}} A_{\mathrm{r}} v_{\mathrm{r}}^{2},
$$

where $\sigma$ is the surface radiation efficiency, $\rho_{\mathrm{a}}$ is the air density, $c_{\mathrm{a}}$ is the velocity of sound waves in air, $A_{\mathrm{r}}$ is the surface area of noise radiation, and $v_{\mathrm{r}}$ is the surface vibration velocity.

The formula for calculating piston and liner inner wall collision sound power $W_{\mathrm{v}}$ is as follows:

$$
W_{\mathrm{v}}=Z v_{\mathrm{v}}^{2}
$$

where $Z$ is the impact impedance between piston and liner, $Z_{i, j}=\left(F_{\mathrm{v}}\right)_{i, j} /\left(v_{\mathrm{v}}\right)_{i, j} \cdot v_{v}$ is the impact speed.

According to formulas (17)-(19), the following formula can be obtained:

$$
\eta_{\mathrm{a} / \mathrm{v}}=\frac{\sigma \rho_{\mathrm{a}} c_{\mathrm{a}} A_{\mathrm{r}} v_{\mathrm{r}}^{2}}{Z v_{\mathrm{v}}^{2}}
$$

Assume that the energy generated at the inner wall of the cylinder liner is not changed when it is transmitted to the body surface through the body structure:

$$
\frac{1}{2} \rho_{\mathrm{v}} h_{\mathrm{t}, \mathrm{v}} A_{\mathrm{v}} v_{\mathrm{v}}^{2}=\frac{1}{2} \rho_{\mathrm{r}} h_{\mathrm{t}, \mathrm{r}} A_{\mathrm{r}} v_{\mathrm{r}}^{2}
$$

where $\rho_{\mathrm{v}}$ is the density of the body structure, $h_{\mathrm{t}, \mathrm{v}}$ is the thickness of the body structure, $A_{\mathrm{v}}$ is the surface area of the body structure, $v_{\mathrm{v}}$ is the vibration speed of the body structure, $\rho_{\mathrm{r}}$ is the density of the liner structure, $h_{\mathrm{t}, \mathrm{r}}$ is the thickness of the liner structure, $A_{\mathrm{r}}$ is the surface area of the 
liner structure, and $v_{\mathrm{r}}$ is the vibration speed of the liner structure.

By combining formula (20) and formula (21), the attenuation factor of sound propagation of the body structure can be calculated:

$$
\left(\eta_{\mathrm{a} / \mathrm{v}}\right)_{i, j}=\frac{\sigma \rho_{\mathrm{a}} c_{\mathrm{a}} \rho_{\mathrm{v}} h_{\mathrm{t}, \mathrm{v}}}{\rho_{\mathrm{r}} h_{\mathrm{t}, \mathrm{r}}} \frac{\left(A_{\mathrm{v}}\right)_{i, j}}{Z_{i, j}} .
$$

Now, the attenuation factor of sound propagation of the body structure and the sound power of the piston and cylinder liner at the point of impact are obtained. The sound power level at each node $(i, j)$ on the body structure surface is defined as follows:

$$
\left(L_{\mathrm{w}}\right)_{i, j}=10 \lg \left(\frac{\left(W_{\mathrm{a}}\right)_{i, j}}{W_{\text {ref }}}\right),
$$

where $W_{\text {ref }}$ is the reference sound power, and it is usually $10^{-12} \mathrm{~W}$.

Then, the sound pressure level needs to be calculated:

$$
\operatorname{SPL}_{i, j}=\left(L_{\mathrm{w}}\right)_{i, j}+10 \lg \left(\frac{1}{2 \pi R_{\mathrm{b}}^{2}}\right) \text {, }
$$

where $R_{\mathrm{b}}$ is the distance between the calculation area location and the structural surface of the internal combustion engine body.

Finally, the piston slap noise of the internal combustion engine can be calculated:

$$
\mathrm{SPL}_{\mathrm{T}}=10 \lg \left(\sum_{i} \sum_{j} 10^{\left(\mathrm{SPL}_{\mathrm{TS}}\right)_{i, j} / 10}+\sum_{i} \sum_{j} 10^{\left(\mathrm{SPL}_{\mathrm{ATS}}\right)_{i, j} / 10}\right),
$$

where $\mathrm{SPL}_{\mathrm{TS}}$ is the piston slap noise on thrust side and $\mathrm{SPL}_{\mathrm{ATS}}$ is the piston slap noise on antithrust side.

The calculated piston slap noise based on the dynamic model is utilized to evaluate the separated piston slap noise. The calculated results are shown in Figure 22.

From Figure 22, at cylinder head top, the separated piston slap noise is consistent with the calculated piston slap noise. There is a difference at about $1,500 \mathrm{~Hz}$. At main slap side, the separated piston slap noise is basically consistent with the calculated piston slap noise. At vice slap side, the separated piston slap noise is also basically consistent with the calculated piston slap noise. But it has some other frequency components around $1,000 \mathrm{~Hz}$. This may be caused by some other parts, such as exhaust pipe, and it needs to be further researched. On the whole, for the real measured noise signals of internal combustion noise, it can be considered that the separated piston slap noise is generally consistent with the calculated piston slap noise. Thus, piston slap noise is accurately separated by using the proposed single-channel algorithm.

5.3. Error Analysis. From Figures 19 and 22, it can be seen that the separated combustion noise and piston slap noise is basically consistent with the calculated independent combustion noise and piston slap noise. But there are still some errors. The main reasons for the error are as follows: (1) The internal combustion engine has complex structure and numerous parts, which will produce a lot of noise. Besides combustion noise and piston slap noise, there are also fuel injection pump noise, valve mechanism knocking noise, etc. The combustion noise and piston slap noise separated by using the single-channel algorithm will contain a small amount of other noise components. Therefore, it is necessary to further study the high-precision separation algorithm. (2) The independent combustion noise calculation method (the spectral filtering method) and the piston slap noise calculation method (the calculation method of piston slap noise based on the dynamic model) are mainly based on mathematical algorithms and models to calculate independent combustion noise and piston slap noise. The calculated results can reflect the main characteristics of combustion noise and piston slap noise. But the calculated combustion noise and piston slap noise are slightly different from the actual combustion noise and piston slap noise of an internal combustion engine. In order to better evaluate the accuracy of combustion noise and piston slap noise, it is necessary to further build independent combustion noise and piston slap noise simulation test bench to obtain independent combustion noise and piston slap noise. It needs to be further researched.

In engineering, the sound pressure level (SPL) is usually used to represent the noise situation of the internal combustion engine. The calculation formula of sound pressure level is as follows [7]:

$$
\mathrm{SPL}=10 \log \left(\frac{p}{p_{\text {ref }}}\right)^{2}=20 \log \left(\frac{p}{p_{\text {ref }}}\right)
$$

where $p_{\text {ref }}=20 \mu \mathrm{Pa}$.

The calculated sound pressure level of the combustion noise and piston slap noise is shown in Figure 23.

It can be seen from Figure 23 that the sound pressure level of separated combustion noise and piston slap noise is consistent with the calculated combustion noise and piston slap noise. In order to quantitatively analyze the error, the following error calculation formula is adopted [7]:

$$
\text { error }=\frac{\sum_{i=1}^{N} \operatorname{abs}\left(\operatorname{SPL}_{i}(\text { separated })-\operatorname{SPL}_{i}(\text { calculated })\right)}{N},
$$

where abs means to take the absolute value.

The calculation results are shown in Table 6 .

From Table 6, it can be seen that the sound pressure level errors between the calculated combustion noise and each side (cylinder head top, main slap side, and vice slap side) combustion noise are $4.14 \mathrm{~dB}(\mathrm{~A}), 3.86 \mathrm{~dB}(\mathrm{~A}), 3.81 \mathrm{~dB}(\mathrm{~A})$, respectively. The sound pressure level error at the cylinder head top is the largest. This is because the cylinder head top receives interference noise from main slap side and vice slap side. Since the main slap side has a fuel injection pump, the sound pressure level error is also large. The fuel injection pump noise has a greater impact on main slap side piston slap noise, and the sound pressure level error between the calculated piston slap noise and main slap side piston slap 


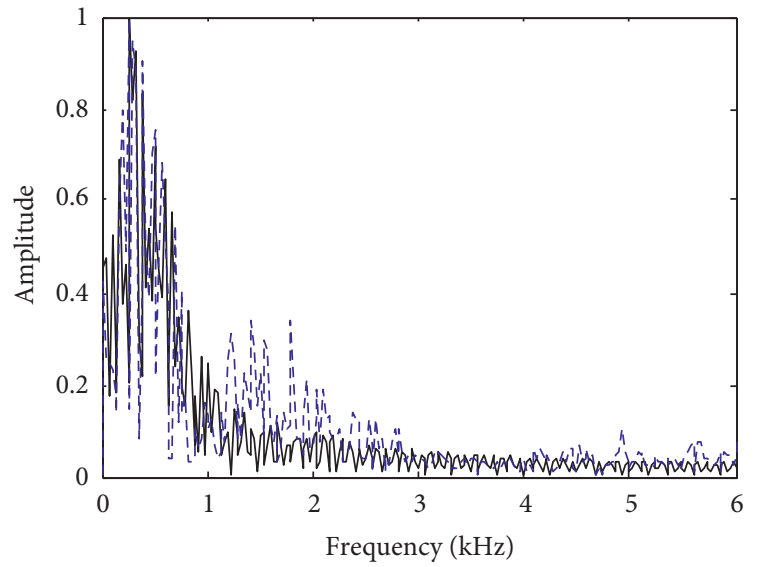

_ Calculated piston slap noise

- - Separated piston slap noise

(a)

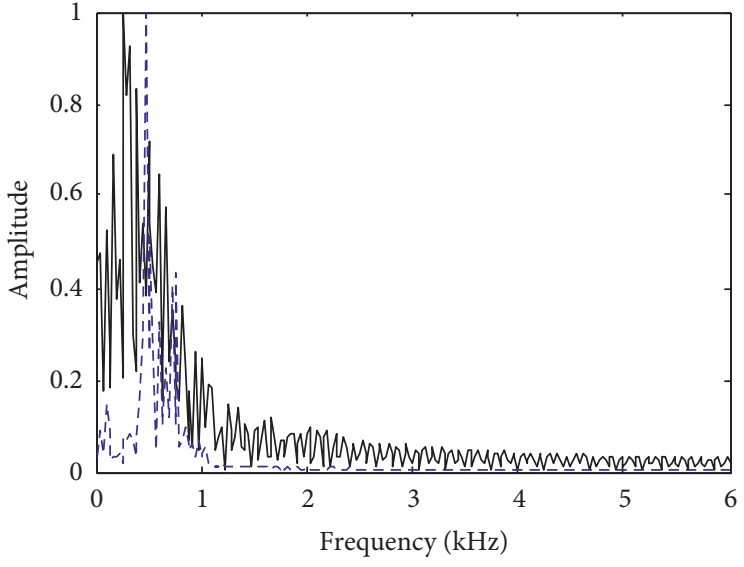

Calculated piston slap noise

- Separated piston slap noise

(b)

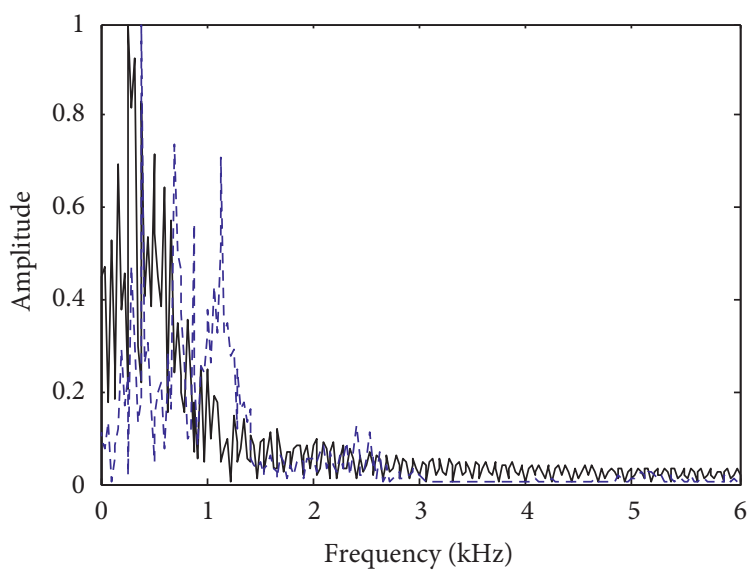

Calculated piston slap noise

- - Separated piston slap noise

(c)

FIgURE 22: The compared results between calculated piston slap noise and separated piston slap noise. At (a) cylinder head top, (b) main slap side, and (c) vice slap side.

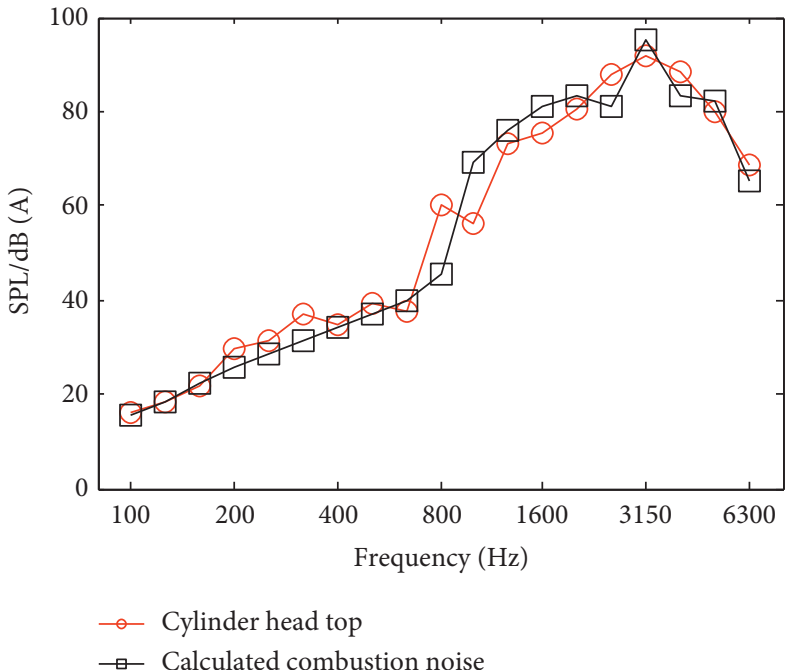

(a)

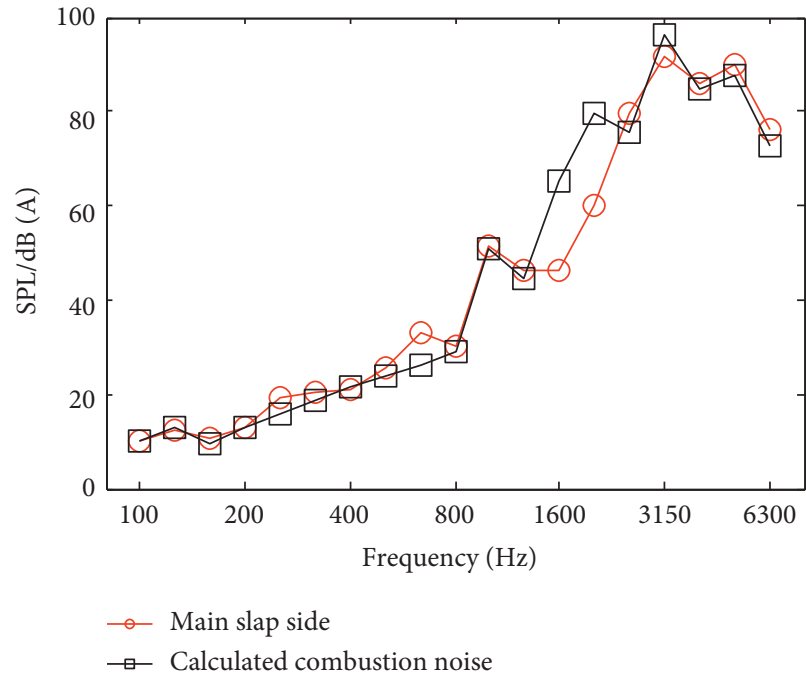

(b)

Figure 23: Continued. 


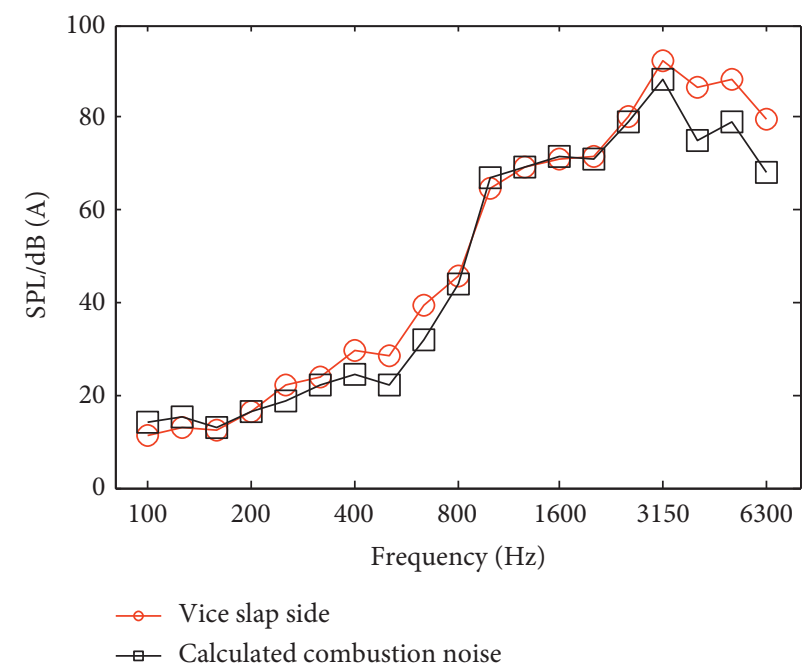

(c)

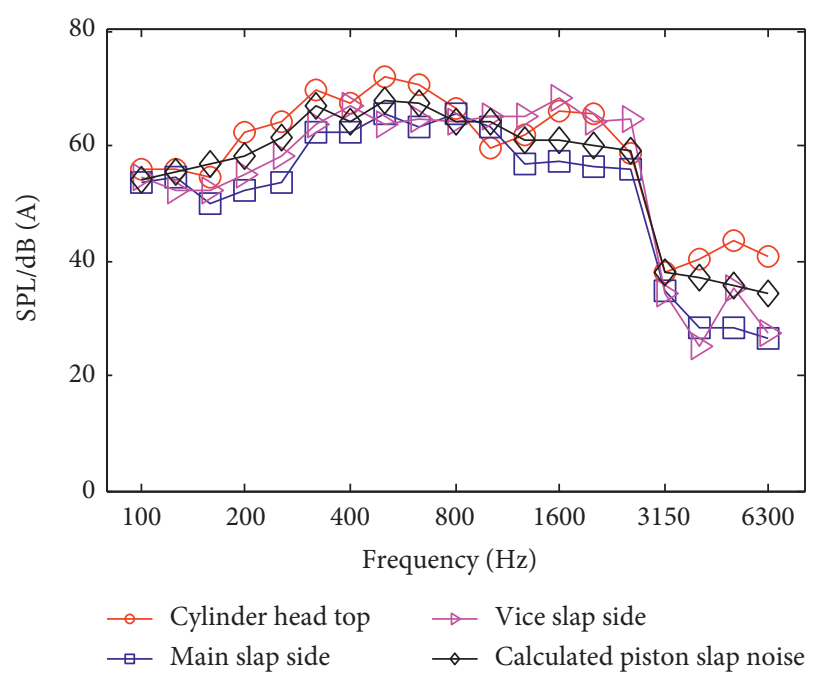

(d)

Figure 23: The calculated sound pressure level. (a) Cylinder head top combustion noise; (b) main slap side combustion noise; (c) vice slap side combustion noise; (d) piston slap noise.

TABLE 6: The sound pressure level error.

\begin{tabular}{|c|c|c|c|c|}
\hline Separated IC1 & Calculated combustion noise $\mathrm{dB}(\mathrm{A})$ & Separated IC2 & Calculated piston slap noise $\mathrm{dB}(\mathrm{A})$ & Average \\
\hline Cylinder head top & 4.14 & Cylinder head top & 3.19 & 3.67 \\
\hline Main slap side & 3.86 & Main slap side & 4.24 & 4.05 \\
\hline Vice slap side & 3.81 & Vice slap side & 3.83 & 3.82 \\
\hline Average & 3.94 & Average & 3.75 & 3.85 \\
\hline
\end{tabular}

noise is $4.24 \mathrm{~dB}(\mathrm{~A})$. On the whole, compared with main slap side and vice slap side, the average error of cylinder head top is $3.67 \mathrm{~dB}(\mathrm{~A})$. The main slap side has the largest error, and the average is up to $4.05 \mathrm{~dB}(\mathrm{~A})$. From the perspective of engineering applications, the error of sound pressure level within $3 \mathrm{~dB}$ indicates the calculation results are very good. In general, the error of sound pressure level within $5 \mathrm{~dB}$ is also acceptable. In the next step, it is needed to study highprecision separation algorithms and build the independent noise source test bench for more in-depth research.

\section{Conclusions}

(1) In order to obtain the radiation noise signal of an internal combustion engine in the marine engine laboratory, the lead coverage method using a threelayer covering is utilized to isolate interference noise from other cylinders. The interference noise is effectively reduced from the noise source level, and the quality and reliability of the radiation noise signal measured by the test are greatly improved.

(2) The single-channel algorithm based on the TVFEMD and RobustICA methods is proposed to separate the noise sources. Moreover, the spectral filtering method and the calculation method of piston slap noise based on the dynamic model are further proposed to calculate independent combustion noise and piston slap noise. The research results show the proposed method can effectively separate noise sources. The separation method and calculation flow of internal combustion engine noise sources are obtained.

\section{Data Availability}

The MAT-file data used to support the findings of this study are available from the corresponding author upon request.

\section{Conflicts of Interest}

The authors declare that they have no conflicts of interest.

\section{Acknowledgments}

This work was supported by the National Natural Science Foundation of China (51279148) and the China Scholarship Fund (201806950033).

\section{References}

[1] S. Verhelst, J. W. Turner, L. Sileghem, and J. Vancoillie, "Methanol as a fuel for internal combustion engines," Progress in Energy and Combustion Science, vol. 70, pp. 43-88, 2019.

[2] D. Vienneau, H. Héritier, M. Foraster et al., "Façades, floors and maps-influence of exposure measurement error on the association between transportation noise and myocardial 
infarction," Environment International, vol. 123, pp. 399-406, 2019.

[3] D. Singh, N. Kumari, and P. Sharma, "A review of adverse effects of road traffic noise on human health," Fluctuation and Noise Letters, vol. 17, no. 1, pp. 1-10, 2018.

[4] J. K. Brueckner and R. Girvin, "Airport noise regulation, airline service quality, and social welfare," Transportation Research Part B: Methodological, vol. 42, no. 1, pp. 19-37, 2008.

[5] S. Delvecchio, P. Bonfiglio, and F. Pompoli, "Vibro-acoustic condition monitoring of internal combustion engines: a critical review of existing techniques," Mechanical Systems and Signal Processing, vol. 99, pp. 661-683, 2018.

[6] A. Acri, E. Nijman, M. Klanner, G. Offner, and R. Corradi, "On the influence of cyclic variability on surface noise contribution analysis of internal combustion engines," Applied Acoustics, vol. 132, pp. 97-108, 2018.

[7] E. G. Giakoumis, D. C. Rakopoulos, and C. D. Rakopoulos, "Combustion noise radiation during dynamic diesel engine operation including effects of various biofuel blends: a review," Renewable and Sustainable Energy Reviews, vol. 54, pp. 1099-1113, 2016.

[8] C. Servière, J.-L. Lacoume, and M. El Badaoui, "Separation of combustion noise and piston-slap in diesel engine-part II: separation of combustion noise and piston-slap using blind source separation methods," Mechanical Systems and Signal Processing, vol. 19, no. 6, pp. 1218-1229, 2005.

[9] W. Li, F. Gu, A. D. Ball, A. Y. T. Leung, and C. E. Phipps, “A study of the noise from diesel engines using the independent component analysis," Mechanical Systems and Signal Processing, vol. 15, no. 6, pp. 1165-1184, 2001.

[10] X. Wang, F. Bi, C. Liu et al., "Blind source separation and identification of internal combustion engine noise based on independent component and wavelet analysis," in Proceedings of the IEEE 2011 International Conference on Electrical and Control Engineering (ICECE), pp. 113-116, Yichang, China, September 2011.

[11] L. Pruvost, Q. Leclère, and E. Parizet, "Diesel engine combustion and mechanical noise separation using an improved spectrofilter," Mechanical Systems and Signal Processing, vol. 23, no. 7, pp. 2072-2087, 2009.

[12] G. Shu and X. Liang, "Identification of complex diesel engine noise sources based on coherent power spectrum analysis," Mechanical Systems and Signal Processing, vol. 21, no. 1, pp. 405-416, 2007.

[13] J. Xi, Z. Feng, G. Wang, and F. Wang, "Vibration and noise source identification methods for a diesel engine," Journal of Mechanical Science and Technology, vol. 29, no. 1, pp. 181-189, 2015.

[14] X. Du, Z. Li, F. Bi, J. Zhang, X. Wang, and K. Shao, "Source separation of diesel engine vibration based on the empirical mode decomposition and independent component analysis," Chinese Journal of Mechanical Engineering, vol. 25, no. 3, pp. 557-563, 2012.

[15] F. Bi, L. Li, J. Zhang, and T. Ma, "Source identification of gasoline engine noise based on continuous wavelet transform and EEMD-robustICA," Applied Acoustics, vol. 100, pp. 3442, 2015.

[16] J. Zhang, J. Wang, J. Lin et al., "Diesel engine noise source identification based on EEMD, coherent power spectrum analysis and improved AHP," Measurement Science and Technology, vol. 26, no. 9, pp. 1-16, 2015.

[17] X. Zheng, Z. Y. Hao, Y. Jin et al., "Application of EEMD and GST method in noise characteristics analysis of internal combustion engine," Chinese Internal Combustion Engine Engineering, vol. 32, no. 5, pp. 68-73, 2011.

[18] J. Yao, Y. Xiang, S. Qian, S. Wang, and S. Wu, "Noise source identification of diesel engine based on variational mode decomposition and robust independent component analysis," Applied Acoustics, vol. 116, pp. 184-194, 2017.

[19] J. Yao, Y. Xiang, S. Qian, and S. Wang, "Radiation noise separation of internal combustion engine based on gammatone-robustICA method," Shock and Vibration, vol. 2017, Article ID 7565041, 14 pages, 2017.

[20] N. E. Huang, Z. Shen, S. R. Long et al., "The empirical mode decomposition and the Hilbert spectrum for nonlinear and non-stationary time series analysis," Proceedings of the Royal Society of London. Series A: Mathematical, Physical and Engineering Sciences, vol. 454, no. 1971, pp. 903-995, 1998.

[21] G. Rilling and P. Flandrin, "One or two frequencies? The empirical mode decomposition answers," IEEE Transactions on Signal Processing, vol. 56, no. 1, pp. 85-95, 2007.

[22] Z. Wu and N. E. Huang, "Ensemble empirical mode decomposition: a noise-assisted data analysis method," Advances in Adaptive Data Analysis, vol. 1, no. 1, pp. 1-41, 2009.

[23] J. Gilles, "Empirical wavelet transform," IEEE Transactions on Signal Processing, vol. 61, no. 16, pp. 3999-4010, 2013.

[24] H. Li, Z. Li, and W. Mo, "A time varying filter approach for empirical mode decomposition," Signal Processing, vol. 138, pp. 146-158, 2017.

[25] Y. Xu, Z. Cai, and K. Ding, "An enhanced bearing fault diagnosis method based on TVF-EMD and a high-order energy operator," Measurement Science and Technology, vol. 29, no. 9, pp. 10-24, 2018.

[26] X. Zhang, Z. Liu, Q. Miao, and L. Wang, "An optimized time varying filtering based empirical mode decomposition method with grey wolf optimizer for machinery fault diagnosis," Journal of Sound and Vibration, vol. 418, pp. 55-78, 2018.

[27] W. Zheng, X. Peng, D. Lu et al., "Composite quantile regression extreme learning machine with feature selection for short-term wind speed forecasting: a new approach," Energy Conversion and Management, vol. 151, pp. 737-752, 2017.

[28] M. Lazhari and A. Sadhu, "Decentralized modal identification of structures using an adaptive empirical mode decomposition method," Journal of Sound and Vibration, vol. 447, pp. 20-41, 2019.

[29] Z. Li, X. Yan, X. Wang, and Z. Peng, "Detection of gear cracks in a complex gearbox of wind turbines using supervised bounded component analysis of vibration signals collected from multi-channel sensors," Journal of Sound and Vibration, vol. 371, pp. 406-433, 2016.

[30] S. Gepshtein and Y. Keller, "Iterative spectral independent component analysis," Signal Processing, vol. 155, pp. 368-376, 2019.

[31] A. Hyvarinen, "Fast and robust fixed-point algorithms for independent component analysis," IEEE Transactions on Neural Networks, vol. 10, no. 3, pp. 626-634, 1999.

[32] J.-F. Cardoso, "High-order contrasts for independent component analysis," Neural Computation, vol. 11, no. 1, pp. 157-192, 1999.

[33] V. Zarzoso and P. Comon, "Comparative speed analysis of fastICA," in Proceedings of the International Conference on Independent Component Analysis and Signal Separation, pp. 293-300, Springer, London, UK, September 2007.

[34] V. Zarzoso and P. Comon, "Robust independent component analysis for blind source separation and extraction with application in electrocardiography," in Proceedings of the 30th Annual International Conference of the IEEE Engineering in 
Medicine and Biology Society, pp. 3344-3347, Vancouver, Canada, August 2008.

[35] V. Zarzoso and P. Comon, "Robust independent component analysis by iterative maximization of the kurtosis contrast with algebraic optimal step size," IEEE Transactions on Neural Networks, vol. 21, no. 2, pp. 248-261, 2010.

[36] D. Zhu, H. S. Cheng, T. Arai, and K. Hamai, "A numerical analysis for piston skirts in mixed lubrication-part I: basic modeling," Journal of Tribology, vol. 114, no. 3, pp. 553-562, 1992.

[37] D. Zhu, Y.-Z. Hu, H. S. Cheng, T. Arai, and K. Hamai, “A numerical analysis for piston skirts in mixed lubrication: part II-deformation considerations," Journal of Tribology, vol. 115, no. 1, pp. 125-133, 1993.

[38] N. Dolatabadi, B. Littlefair, M. De la Cruz, S. Theodossiades, S. J. Rothberg, and H. Rahnejat, "A transient tribodynamic approach for the calculation of internal combustion engine piston slap noise," Journal of Sound and Vibration, vol. 352, pp. 192-209, 2015.

[39] N. Dolatabadi, S. Theodossiades, and S. J. Rothberg, "Design optimization study of a nonlinear energy absorber for internal combustion engine pistons," Journal of Computational and Nonlinear Dynamics, vol. 13, no. 9, article 090910, 2018. 


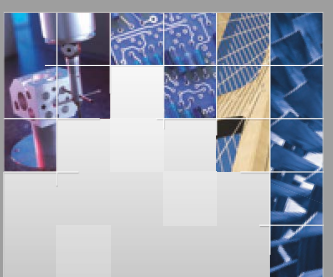

\section{Enfincering}
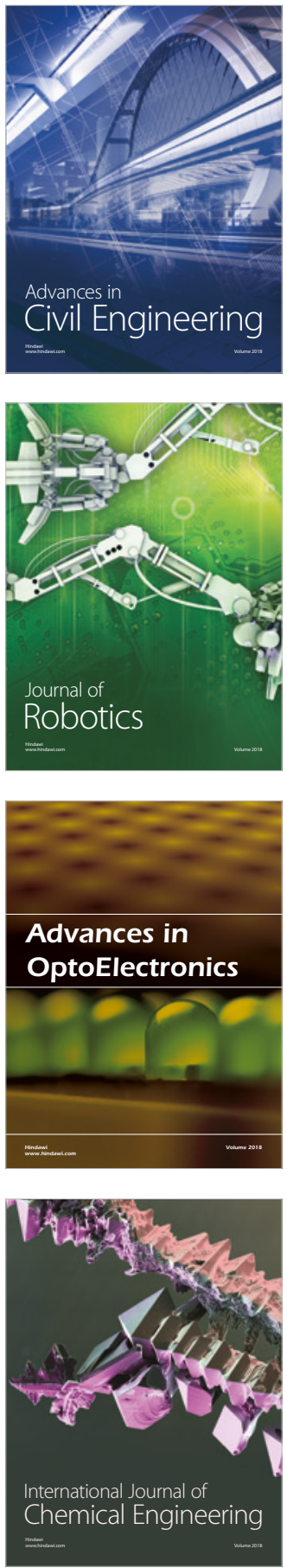

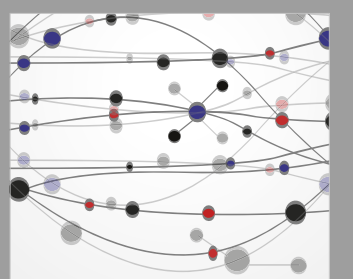

\section{Rotating \\ Machinery}

The Scientific World Journal

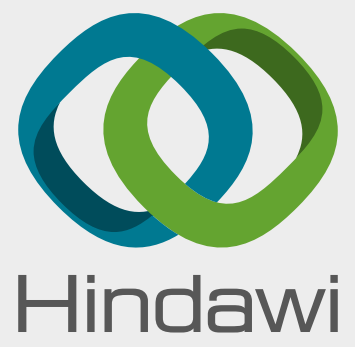

Submit your manuscripts at

www.hindawi.com
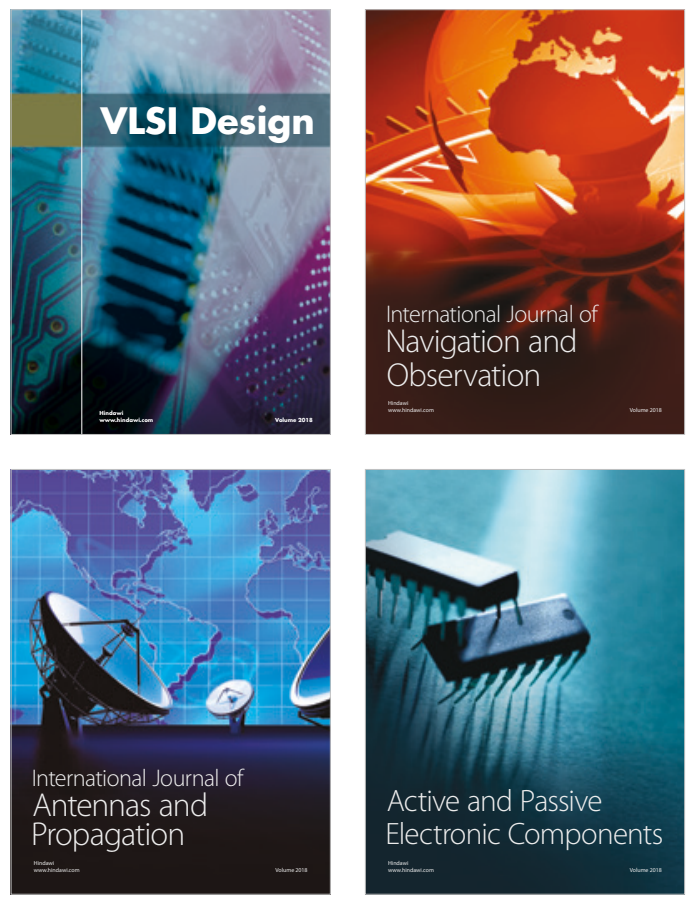
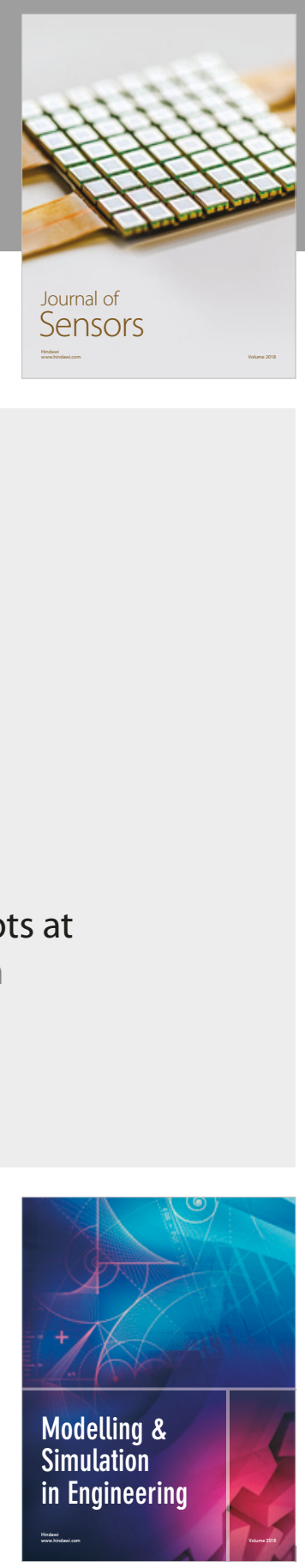

\section{Advances \\ Multimedia}
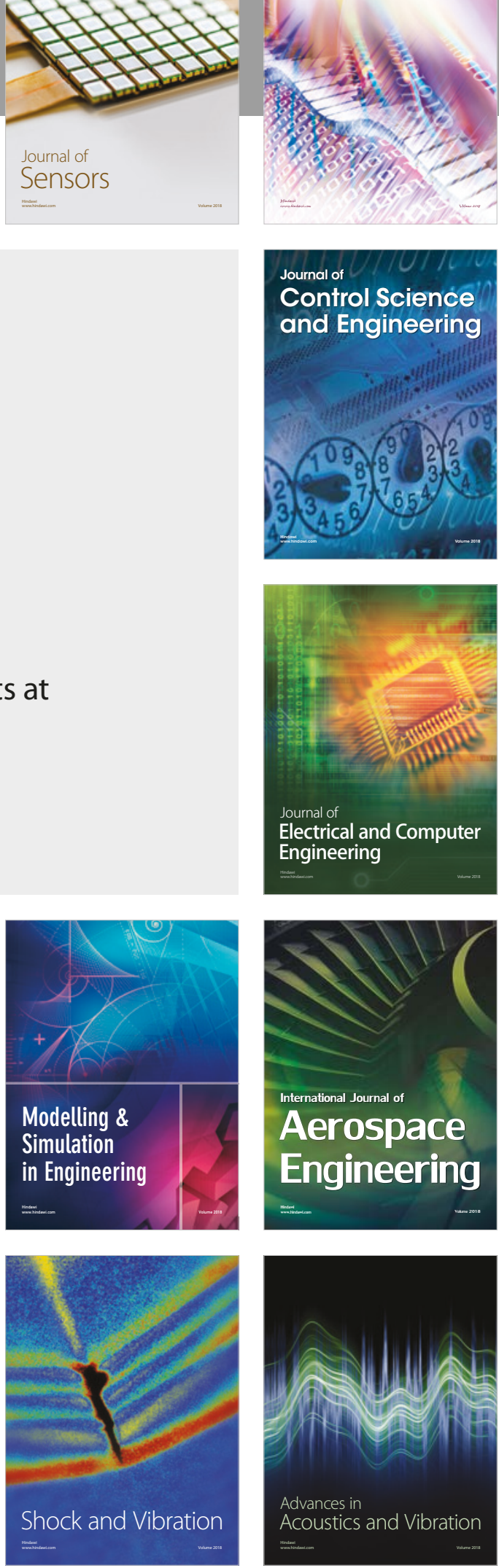